\title{
LA SCALA GRADUUM CALORIS DE NEWTON. UNA SIMULACIÓN NUMÉRICA
}

\author{
Julián Simón Calero \\ Universidad Nacional de Educación a Distancia (UNED) \\ Email: julian_simon@telefonica.net \\ ORCID iD: https://orcid.org/0000-0001-8162-7881
}

Recibido: 17 febrero 2019; Aceptado:31 enero 2021

Cómo citar este artículo/Citation: Simón Calero, Julián (2021) "La Scala Graduum Caloris de Newton. Una simulación numérica", Asclepio, 73(1): p350. https://doi.org/10.3989/asclepio.2021.16

RESUMEN: Sir Isaac Newton, en la Scala graduum Caloris, publicada en 1701, presentaba una escala "con el grado de calor" de los cuerpos que extendía las medidas muy por encima de los valores disponibles en la época. Para determinarla, Newton siguió dos caminos. El primero usando un termómetro de dilatación con aceite de linaza como líquido, cuyas medidas seguían una progresión aritmética, pero cuyo máximo estaba limitado por la inflamación del aceite. El segundo, por un método completamente nuevo, que consistía en medir los tiempos de enfriamiento de un cuerpo previamente calentado en una pequeña cocina de carbón, y relacionar esos tiempos con las temperaturas según una nueva ley, lo que daba lugar a una escala que seguía una progresión geométrica. Ambas escalas se solapaban parcialmente, lo cual le permitió extender las medidas aritméticas hasta más de seis veces el punto de ebullición del agua. Esa nueva ley se conoce como "Ley de enfriamiento Newton".

Aquí, pretendemos realizar una simulación numérica del proceso de enfriamiento del cuerpo caliente, conjeturando los instrumentos que pudo haber usado y las condiciones ambientales en que se realizó. Todo ello siguiendo lo que el propio Newton refleja en su artículo. Se terminará con unas reflexiones sobre la ley, que estimamos que la enunció en forma integral.

PALABRAS CLAVE: Newton; Enfriamiento; Termómetros; Escalas; Simulaciones.

\section{NEWTON'S SCALA GRADUUM CALORIS. A NUMERICAL SIMULATION}

ABSTRACT: Sir Isaac Newton, in the Scala graduum Caloris, published in 1701, presented a scale with "the degree of heat" of the bodies which extended the measurements far beyond the values available at that time. To determine it, Newton followed two paths. The first was by using an expansion thermometer with linseed oil as the liquid, whose measurements followed an arithmetical progression, but its maximum was limited by the inflammation of the oil. The second using a completely new method, which consisted of measuring the cooling times of a body previously heated in a small kitchen fire, and relating these times to the temperatures according to a new law, which gave rise to a new scale that followed a geometric progression. Both scales were partially overlapped, allowing him to extend the arithmetic measurements up to more than six times the water boiling point. This new law is known as Newton's Cooling Law.

Here, we intend to carry out a numerical simulation of the hot body cooling process, conjecturing the instruments he may have used and the environmental conditions in which it took place. All this following what Newton himself reflects in his article. We will end with some reflections on the law, which we believe he enunciated in an integral manner.

KEY WORDS: Newton; Cooling; Thermometers; Scales; Simulations. 


\section{INTRODUCCIÓN}

La Scala graduum caloris. Calorum descriptiones \& signa apareció en las Philosophical Tansactions en 1701 de forma anónima ${ }^{1}$, aunque su autor era Isaac Newton ${ }^{2}$.

El artículo consta de cinco páginas. En las tres primeras se expone la Scala como una tabla que incluye una serie de cuerpos, cada uno descrito en un estado bien definido, con el calor que corresponde a cada uno en ese estado. Este calor, o mejor el grado de calor ya que se trata de una medida, está expresado en dos escalas, una aritmética y otra geométrica. Las explicaciones sobre la tabla y cómo se habían obtenido los resultados ocupan las dos últimas páginas ${ }^{3}$. En estas se enuncia la denominada "ley del enfriamiento" que se puede expresar diciendo que el enfriamiento de un cuerpo es proporcional a la diferencia de temperatura con el medio que lo rodea. Esta ley, conocida como ley de Newton, es lo más relevante del artículo; sin embargo, hay otros aspectos que también merecen interés, especialmente el intento de extender la escala de medida de temperaturas más allá de las limitaciones impuestas por los termómetros de la época.

Durante el siglo XVIII varios autores trataron de confirmar o rebatir esta ley; uno de los primeros en hacerlo fue G. W. Richmann, seguido más tarde por G. Martine y I. C. P. Erxleben. En el siglo XIX, tras los estudios de propagación del calor en el vacío, continuó la polémica; incluso en estas nuevas condiciones hubo quienes seguían manteniendo la vigencia de la ley, como J. Leslie y P. Prévost, mientras otros la negaron, como F. Delaroche. Al decir de Ugo Benson ${ }^{4}$, los científicos más empiristas buscaban alternativas que se adecuasen a las medidas experimentales, mientras que los más teóricos preferían mantener la vigencia de la ley. Entre los primeros, P. Dulong y A. Petit, que realizaron una amplia experimentación sobre la transmisión del calor tanto en vacío como en el aire y terminaron proponiendo leyes diferentes a la de Newton. A mediados de siglo Lord Kelvin introdujo la noción de temperatura absoluta y la escala termodinámica asociada. A finales de siglo J. Stefan formuló la ley de la radiación, por la que los cuerpos emitían un flujo de calor que era proporcional a la cuarta potencia de la temperatura absoluta; esta ley fue demostrada más tarde por L. Boltzmann. Quedaba establecido que había dos mecanismos para la emisión del calor: convección y radiación, siendo la ley de Newton aplicable solo al primero.

En el siglo XIX encontramos un primer análisis general del artículo de Newton en David Brewster (1855), quien comentó la naturaleza de las dos escalas y deta- lló el modus operandi de Newton. Además, se enzarzó en una polémica con $M$. Biot sobre la época en que Newton realizó sus experimentos, que para Biot tuvieron que ser antes de 1693, puesto que en su opinión después de ese año Newton entró en un período de demencia en el que solo era capaz de escribir sobre teología. Brewster trató de rebatir esa aseveración basándose en un cuaderno de notas de Newton con sus anotaciones de 1692/93. Por otra parte, como recuerda Brewster, Biot ${ }^{5}$ en su biografía de Newton afirmaba que la Scala contenía tres descubrimientos importantes: la calibración de los termómetros mediante temperaturas referidas a fenómenos físicos definidos, la mencionada ley de enfriamiento, y la constancia de la temperatura durante los procesos de fusión o ebullición.

Ya en el siglo XX, James A. Ruffner (1963) trató el tema en un interesante artículo del que destacamos tres aspectos. El primero concierne a la naturaleza y origen de la ley, cuestión en la que completó la argumentación de Brewster contra Biot, para lo que se apoyó en el análisis de los cuadernos de notas de Newton complementados con otras fuentes de esa década, como notas provenientes de alguno de sus visitantes. Comparando las escalas de las anotaciones de 1692/93 con la aritmética de la Scala de1701, Ruffner ${ }^{6}$ conjeturó que la ley debió de ser concebida antes de 1687 y que Newton la elevó a la categoría de principio básico en 1690 como resultado de sus experimentos y medidas. El segundo aspecto se refiere a los termómetros como instrumentos de medida y de cómo Newton tuvo que idear uno nuevo basado en aceite de linaza, ya que el de Hooke, basado en alcohol y que era el estándar en la Royal Society, estaba limitado a temperaturas ambientales y no le servía para rangos altos, tales como la fusión de metales. Este nuevo instrumento tuvo como consecuencia una nueva definición de los puntos de referencia de la escala más acorde con las nuevas medidas. El tercer aspecto es un intento de reconstrucción del procedimiento de medida con el bloque de hierro caliente como nuevo termómetro, y la correlación entre las escalas aritmética y geométrica. Ruffner ${ }^{7}$ eligió dos puntos como referencia, ambos con sus grados de calor definidos en las dos escalas. Asignó a cada uno un tiempo inversamente proporcional al valor de la escala geométrica, y a partir de ellos presentó las transformaciones matemáticas que relacionan las dos escalas. Ello lo completó con la conversión de los grados aritméticos a la escala centígrada, lo que permitió comparar los valores que obtuvo Newton con los actuales. Esta operación muestra una buena correlación a temperaturas bajas, pero las discrepancias aumentan a medida que la temperatura sube, hecho debido a la existencia de un enfriamiento adicional del 
hierro por radiación que se suma a la de convección, que es la que contempla la ley del enfriamiento.

Dos décadas después Ugo Grigull (1984) también estudió la correlación entre las temperaturas medidas por Newton y las reales basándose en los puntos de fusión de las aleaciones incluidas en la tabla, que son reproducibles en laboratorio y bien conocidas hoy día. Además, con el fin de lograr una mayor exactitud, presentó datos experimentales sobre el coeficiente de dilatación del aceite de linaza, que encontró que no es constante, lo cual introdujo en sus cálculos de conversión de las medidas obtenidas por Newton.

El trabajo que aquí presentamos pretende conjeturar cómo eran los aparatos y la instalación que pudo haber utilizado Newton en sus mediciones, tomando como referencia el texto de la Scala con algunos toques de imaginación añadidos, pero verosímiles. Hecho lo cual, se tratará de simular matemáticamente el proceso de medida en esa instalación, con esos aparatos y en las probables condiciones ambientales. Para llevar adelante este programa se comenzará con un análisis y comentario de la Scala, y se continuará con un estudio teórico de los dos procedimientos de medida con sus escalas asociadas, la relación entre ambas y el modus operandi. Como resultado se efectuará la correlación entre las temperaturas dadas por Newton y los valores actuales, a lo que seguirá el proceso de simulación comparando los resultados numéricos con los de Newton. Como punto final se harán unas consideraciones sobre la naturaleza de la Ley de Newton.

\section{LA TABLA DE CALORES}

La Scala graduum caloris consta de 22 entradas indexadas en dos escalas de temperaturas: la aritmética y la geométrica, que designaremos como lineal y logarítmica para acercarnos más a la terminología actual. Aquí presentamos nuestra versión en la Tabla I que incluye algunas modificaciones y añadidos a la original. Las tres columnas encabezadas por N, $\boldsymbol{y}$ y Estados corresponden respectivamente a la escala aritmética, a la geométrica y a la descripción de los cuerpos, objetos o circunstancias en las que se produce la temperatura de ese estado, y son las dadas por Newton. De las columnas añadidas la primera es una numeración de las 22 entradas con el fin de facilitar las referencias, el resto se explicará más adelante al hilo de la exposición.

La escala lineal tiene su origen en la nieve fundente, cuyo calor es cero, y a sus valores los denominaremos como "grados Newton" (oN). Puntos significativos son el calor del cuerpo humano (P.6) cuyo valor son 12
oN, la ebullición del agua (P.12) con 34 oN, varios puntos de fusión de aleaciones hasta terminar en una pequeña cocina (P.22) con 192 oN. En toda esta escala, el termómetro de aceite de linaza solo es utilizable hasta el punto de fusión del estaño (P.16) con 72 N. La escala logarítmica se inicia en el calor del cuerpo humano, con valor unidad, $\gamma=1$, y acaba en la cocina con $\gamma=5$. Ambas escalas se solapan entre el cuerpo humano y la fusión del estaño. Entendemos que esa pequeña cocina se refiere a una pequeña fragua.

A tenor del texto descriptivo de la Scala, en nuestro análisis hemos desdoblado cuatro estados. El primero, la ebullición del agua en tres partes (P.12A, P.12B y P.12C); el segundo, la fusión del estaño en dos (P.16A y P.16B); el tercero, la del antimonio (P.20A y P.20B); y el cuarto, el fuego de la cocina con hulla o leña (P.22A y P.22B). Estos desdoblamientos siguen las propias indicaciones de Newton, que en las respectivas descripciones parece incluir una definición principal y otras secundarias; para la primera indica tanto la temperatura aritmética como la geométrica en las columnas correspondientes, mientras que para las otras la aritmética únicamente se cita en el texto. En consonancia, hemos incluido estas temperaturas secundarias en las columnas o $\mathbf{N}$ y $\mathrm{Y}$ pero entre corchetes.

En un repaso a los estados encontramos algunos bastante vagos, como las temperaturas en invierno, primavera o verano (P.1-5). Los relativos al calor soportable por una mano (P.7-8) parecen más bien pintorescos; sin embargo, según indica Ruffner ${ }^{8}$, ambos estaban ya en las notas del cuaderno de 1693. Otros son cualitativos, como los que tratan de la apreciación visual del brillo de cuerpos calientes (P.19-21). Los relativos a la cera (P.9-11) no son fácilmente reproducibles. Hay otros que están referidos a puntos bien definidos físicamente, tales como los relativos a la fusión de elementos o aleaciones, y que son, por tanto, reproducibles. Todos estos los hemos marcado con un asterisco en la primera columna. No obstante, haremos algunas observaciones más adelante respecto a la temperatura de fusión de las aleaciones.

El calor del cuerpo humano (P.6) solo es reproducible de forma imprecisa. Varía de persona a persona y de cómo se realice su medida, esto suponiendo que se disponga de un termómetro clínico que evidentemente no era el caso de Newton, cuyo instrumento, a tenor de lo que dice Desaguliers ${ }^{9}$, sería una esfera de cristal de unos $5 \mathrm{~cm}$ con un capilar de casi un metro. Es obvio que no sería fácil de usarlo como termómetro corporal, si acaso calentándolo entre las manos, que parece lo más plausible, o pegándolo a alguna parte 


\section{TABLA I. GRADOS DE CALOR}

\begin{tabular}{|c|c|c|c|c|c|c|c|}
\hline $\mathrm{P}$ & on & 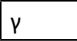 & $\tau(0 \cong \mathrm{C})$ & $\tau(15 \stackrel{\circ}{\circ})$ & Vol. & $\mathrm{T}_{\mathrm{R}}(\stackrel{\circ}{\circ} \mathrm{C})$ & Estados \\
\hline $1 *$ & 0 & & & & 10000 & 0 & $\begin{array}{l}\text { Calor del aire en invierno, cuando el agua empieza a congelarse. Se descubre exacta- } \\
\text { mente colocando el termómetro en nieve comprimida cuando empieza a deshelarse. }\end{array}$ \\
\hline 2 & $0,1,2$ & & & & & & Calor del aire en invierno. \\
\hline 3 & $2,3,4$ & & & & & & Calor del aire en primavera y otoño. \\
\hline 4 & $4,5,6$ & & & & & & Calor del aire en verano. \\
\hline 5 & 6 & & & & & & Calor del aire cerca del mediodía en el mes de julio. \\
\hline $6 *$ & 12 & 1 & 1,000 & 1,000 & 10256 & $36-37$ & $\begin{array}{l}\text { El mayor calor que el termómetro recibe en el contacto con el cuerpo humano. } \\
\text { También más o menos el de un pájaro incubando los huevos. }\end{array}$ \\
\hline 7 & $143 / 11$ & $11 / 4$ & 0,938 & 0,914 & & & $\begin{array}{l}\text { Casi el mayor calor de un baño que un hombre puede soportar moviendo su mano } \\
\text { dentro por algún tiempo. También el calor la de la sangre recién extraída. }\end{array}$ \\
\hline 8 & 17 & $11 / 2$ & 0,875 & 0,836 & & & $\begin{array}{l}\text { El mayor calor de un baño que un hombre puede soportar durante algún tiempo sin } \\
\text { agitar su mano dentro. }\end{array}$ \\
\hline 9 & $202 / 11$ & $13 / 4$ & 0,812 & 0,764 & & & $\begin{array}{l}\text { Calor de un baño en el que flota cera fundida que enfriándose que se endurece y } \\
\text { pierde su transparencia. }\end{array}$ \\
\hline 10 & 24 & 2 & 0,750 & 0,695 & & 65 & $\begin{array}{l}\text { Calor de un baño en el que flota cera y se funde al calentarse y se mantiene conti- } \\
\text { nuamente en fusión sin ebullición. }\end{array}$ \\
\hline 11 & $286 / 11$ & $21 / 4$ & 0,688 & 0,630 & & & Calor medio entre aquel al que funde la cera y el agua hierve. \\
\hline $12 \mathrm{~A} *$ & 34 & $21 / 2$ & 0,625 & 0,567 & 10725 & $\begin{array}{l}100 \\
98-112\end{array}$ & $\begin{array}{l}\text { Calor en que el agua entra en ebullición enérgicamente, } \\
\text { y una mezcla de dos partes de plomo, tres de estaño y cinco de bismuto endurece } \\
\text { al enfriarse. }\end{array}$ \\
\hline $12 B$ & & & & & & & $\begin{array}{l}\text { Por otra parte, el hierro que se enfría hasta } 35 \text { o } 36 \text { partes de calor, cuando incide } \\
\text { sobre el mismo agua caliente gota a gota, o agua fría con 37, indica el fin de la } \\
\text { ebullición. }\end{array}$ \\
\hline $12 \mathrm{C}$ & \begin{tabular}{|l}
{$[33]$} \\
{$[34,5]$} \\
\end{tabular} & $\begin{array}{l}{[2,46]} \\
{[2,52]} \\
\end{array}$ & $\begin{array}{l}0,635 \\
0,620 \\
\end{array}$ & $\begin{array}{l}0,577 \\
0,562 \\
\end{array}$ & 10705 & & $\begin{array}{l}\text { El agua empieza a hervir con un grado de calor de } 33 \text { partes, rompiendo apenas se } \\
\text { adquiere un grado algo mayor que } 34,5 \text {. }\end{array}$ \\
\hline $13^{*}$ & $404 / 11$ & $23 / 4$ & 0,563 & 0,506 & & 125 & $\begin{array}{l}\text { El menor calor por el que una mezcla de una parte de plomo, cuatro de estaño y } \\
\text { cinco de bismuto funde al calentarse y se mantiene en continua fusión. }\end{array}$ \\
\hline $14 *$ & 48 & 3 & 0,500 & 0,447 & & 138-155 & $\begin{array}{l}\text { El menor grado de calor por el que se funde una mezcla de partes iguales de estaño } \\
\text { y bismuto. Esta mezcla con el calor de } 47 \text { partes se coagula por frío. }\end{array}$ \\
\hline $15 *$ & 57 & $31 / 4$ & 0,438 & 0,389 & & $\begin{array}{l}138-186 \\
135-193 \\
138-193 \\
124-142\end{array}$ & $\begin{array}{l}\text { Calor con el que se funde una mezcla de dos partes de estaño y una de bismuto; } \\
\text { pero } \\
\text { una mezcla de tres partes de estaño y dos de bismuto, } \\
\text { pero cinco partes de estaño y dos de plomo se endurecen por enfriamiento con este } \\
\text { grado de calor. } \\
\text { Y de igual manera una mezcla de partes iguales de plomo y bismuto. }\end{array}$ \\
\hline $16 A^{*}$ & 68 & $31 / 2$ & 0,375 & 0,331 & & $171-216$ & $\begin{array}{l}\text { El menor calor al que funde una mezcla de una parte de bismuto y ocho partes de } \\
\text { estaño. }\end{array}$ \\
\hline $16 \mathrm{~B}^{*}$ & $\begin{array}{l}{[70]} \\
{[72]}\end{array}$ & {$[3,54]$} & 0,365 & 0,322 & $\begin{array}{l}11496 \\
11516\end{array}$ & 232 & $\begin{array}{l}\text { El estaño por sí mismo entra en fusión con el calor de } 72 \text { partes y por enfriamiento } \\
\text { endurece con el calor de } 70 \text { partes. }\end{array}$ \\
\hline $17^{*}$ & 81 & $33 / 4$ & 0,313 & 0,275 & & $\begin{array}{l}271 \\
183-286 \\
167-291\end{array}$ & $\begin{array}{l}\text { Calor que funde el bismuto, como también } \\
\text { una mezcla de cuatro partes de plomo y una parte de estaño; } \\
\text { pero una mezcla de cinco partes de plomo y una parte de estaño, cuando funde y se } \\
\text { enfría otra vez, endurece con este calor. }\end{array}$ \\
\hline $18^{*}$ & 96 & 4 & 0,250 & 0,219 & & 327 & $\begin{array}{l}\text { El menor calor que funde el plomo. El plomo por aumento del calor se funde con el } \\
\text { calor de } 96 \text { o } 97 \text { partes y al enfriarse endurece con } 95 \text { partes. }\end{array}$ \\
\hline $19^{*}$ & 114 & $41 / 4$ & 0,188 & 0,164 & & $354-426$ & $\begin{array}{l}\text { Calor con el que los cuerpos ardientes al enfriarse cesan de brillar en la noche, y de } \\
\text { nuevo, al aumentar el calor comienzan a brillar en la oscuridad, pero con una luz } \\
\text { muy tenue, que es escasamente perceptible. } \\
\text { Este calor funde una mezcla de partes iguales de estaño y regulus martis, } \\
\text { y una mezcla de siete partes de bismuto y cuatro partes del antedicho regulus } \\
\text { endurece al enfriarse. }\end{array}$ \\
\hline $20 A^{*}$ & 136 & $41 / 2$ & 0,125 & 0,109 & & $\begin{array}{l}421-570 \\
425-576\end{array}$ & $\begin{array}{l}\text { Calor por el que los cuerpos ardientes resplandecen en la noche, pero no en el } \\
\text { crepúsculo. } \\
\text { Con este calor endurecen al enfriarse tanto una mezcla de dos partes de regulus } \\
\text { martis y una parte de bismuto, } \\
\text { como una mezcla de cinco partes del dicho regulus y una parte de estaño. }\end{array}$ \\
\hline $20 \mathrm{~B}^{*}$ & [146] & {$[4,60]$} & 0,100 & 0,087 & & 631 & El regulus por sí mismo endurece con el calor de 146 partes. \\
\hline 21 & 161 & $43 / 4$ & 0,063 & & & & $\begin{array}{l}\text { Calor por el que los cuerpos ardientes resplandecen claramente en el crepúsculo } \\
\text { que precede a la salida del sol, o después de su puesta, pero no en todo un día claro, } \\
\text { sino muy tenuemente. }\end{array}$ \\
\hline $22 \mathrm{~A}$ & 192 & 5 & 0 & 0 & & & $\begin{array}{l}\text { Calor de brasas en el fuego de una pequeña cocina con hulla bituminosa y que arde } \\
\text { sin usar fuelles. También el calor del hierro calentado tanto como se pueda en tal } \\
\text { fuego. }\end{array}$ \\
\hline $22 B$ & $\begin{array}{l}200 \\
210\end{array}$ & $\begin{array}{l}{[5,06-} \\
5,13]\end{array}$ & & & & & $\begin{array}{l}\text { El calor del fuego de una pequeña cocina con leña es algo mayor, sea } 200 \text { o } 210 \\
\text { partes. El calor de un gran fuego es aún mayor, especialmente si se sopla con fuelles. }\end{array}$ \\
\hline
\end{tabular}


del cuerpo. A pesar de estas incertidumbres, la temperatura del cuerpo humano cumple una función muy significativa, ya que es la base en la escala geométrica y está definida en la aritmética. Sobre esta última Newton dice:

En la primera columna de esta tabla están los grados de calor en proporción aritmética, comenzando por el calor con el que el agua empieza a helarse como grado de calor mínimo o límite común entre calor y frío, y poniendo que el calor humano externo sea la parte duodécima.

Esto es, los puntos de referencia son el P.1 y el P.6, cuyos grados de calor son 0 oN y 12 N, y a los que se ajustarán los demás, como expone más adelante en el texto. Respecto a la escala logarítmica:

Se ve con esta tabla que el calor del agua hirviendo es casi el triple que el calor del cuerpo humano, y que el calor del estaño fundente es séxtuplo, y que el del plomo fundente óctuplo, y el calor del regulus fundente duodécuplo, y el calor ordinario del fuego de la cocina es dieciséis o diecisiete veces mayor que el calor del mismo cuerpo humano.

Estos puntos los anota de forma precisa en la escala logarítmica como $\gamma=1$ para el cuerpo humano, $\gamma=3,58$ para el estaño, $\gamma=4$ para el plomo fundente, $y$ $\gamma=5$ para la pequeña cocina.

El punto relativo al agua merece algo más de atención. Primero establece que con calor de 34 oN entra en ebullición enérgicamente (P.12A). Sin embargo, a renglón seguido (P.12C) dice que empieza a hervir con 33 y rompe apenas pasa los 34,5, lo cual no es del todo congruente con lo anterior. Entre ambas intercala el enunciado que hemos designado como P.12B, y que para su interpretación se precisa conocer el modus operandi y el aparato empleado, de lo cual nos ocuparemos más adelante. Adelantamos que este era un tocho de hierro, que imaginamos que sería parecido al que mostramos en la Fig. 1, y que una vez calentado en la cocina se dejaba enfriar pasando por todos los estados hasta llegar a la temperatura del cuerpo humano. Es fácil imaginar que si sobre ese hierro muy caliente se dejase caer agua, esta comenzaría a hervir y se evaporaría completamente, y que si hubiera estado frío el agua habría permanecido líquida. Ahora bien, Newton afirma que cuando sobre "el hierro que se enfría hasta 35 o 36 partes de calor... incide agua caliente gota a gota, ... indica el fin de la ebullición". Esto es, que se está en el grado de calor en el que empieza a aparecer el agua líquida; por tanto, la ebullición estaría sobre los 35 N. A eso añade si el agua vertida estuviese fría se necesitaría que el hierro estuviese a 37 N, algo más caliente, para que el fenómeno se repitiese.

Finalmente, el término regulus (P.19) en el lenguaje alquímico de Newton se refiere al antimonio y sus aleaciones. El regulus martis es el antimonio obtenido por la reducción de la estibina, que es el sulfuro de antimonio, por medio del hierro. Los productos de esa reacción son el antimonio puro y el sulfuro de hierro ${ }^{10}$.

\section{LA MEDIDA DE LAS TEMPERATURAS}

Como consideración previa, hemos de recordar que la diferencia entre calor y temperatura no se estableció hasta mediado el siglo XVIII ${ }^{11}$, por lo cual la expresión grado de calor, o simplemente calor, que usa Newton puede referirse a uno $u$ otro. De acuerdo con el contexto, en general lo entenderemos como temperatura, aunque a veces se trate de cantidad de calor.

La medida de la temperatura en el ámbito de la Royal Society se hacía con el "termoscopio" de Robert Hooke. Este instrumento consistía en un bulbo con un tubo capilar y las medidas se basaban en la dilatación del alcohol coloreado que llenaba el bulbo y que ascendía por el tubo. La utilización de este instrumento estaba limitada a la meteorología o a usos clínicos ${ }^{12}$, pero no era adecuado para las medidas en el ámbito químico que Newton necesitaba. Por ello ideó un nuevo termómetro que utilizaba aceite de linaza en vez de alcohol, y con el que se extendía el rango de medida hasta la fusión del estaño (232 으). El principio físico en que se basa este tipo instrumento es la dilatación de un líquido, por lo que las temperaturas se asimilan a longitudes. Este termómetro es fácilmente tarable tomando dos temperaturas como marcas de referencia y a las que se referirá cualquier otra medida.

Empero la mejora conseguida con el uso del aceite, Newton aspiraba a llegar a temperaturas aún más altas donde ya no era viable el uso de líquidos, que o bien se inflamaban o vaporizaban. Su ingenio le movió hacia un nuevo artefacto regido por una ley física diferente, que consistía en un tocho de hierro, que denominaremos probeta, el cual se calentaba a una determinada temperatura, supuesta conocida o conocible, y luego se dejaba enfriar en una corriente de aire. La temperatura se medía por el tiempo que tardaba la temperatura del tocho en descender desde la temperatura inicial hasta que se igualaba con la del objeto a medir. El principio físico aplicado era que la velocidad de enfriamiento era proporcional a la temperatura del tocho, aunque con más rigor sería a su diferencia con la 
temperatura ambiente. En razón de ese principio le denominaremos termómetro de enfriamiento.

Desde un punto de vista teórico el termómetro de enfriamiento es tan válido como el termómetro de dilatación. Recalcamos las dos leyes físicas sobre las que se basan ambos instrumentos: la dilatación y el enfriamiento. La primera se expresaría matemáticamente como $d V=\alpha d T$ y la segunda como $d T=-k T d t$. Dado que el líquido se expande por un tubo de sección interior $S$, la variación de volumen se puede expresar como $d V=S d x$, de lo cual resulta que la medida de la temperatura se reducirá a una longitud, mientras que en el segundo caso será un tiempo. Otra diferencia entre ambos es que la medida con el primero es estacionaria y en el segundo es dinámica. Tanto en uno como en otro hay que definir una escala de medida y dos temperaturas de referencia; para el primero estas definirían un segmento de longitud entre las marcas de la dilatación para una y otra, mientras que para el segundo sería el intervalo de tiempo transcurrido en el enfriamiento desde la más alta a la más baja.

Para el termómetro de dilatación, en la hipótesis de que el coeficiente de dilatación fuese constante, la temperatura se expresaría como $T=T_{0}+\left(T_{C}-T_{0}\right)\left(\frac{x-x_{0}}{x_{C}-x_{0}}\right)$, donde los subíndices 0 y $C$ se refieren a las temperaturas fría y caliente respectivamente. Esa expresión se simplifica si se toman $T_{0}$ y $x_{0}$ como cero y se ajusta la escala de modo que $T_{\mathrm{c}} / x_{\mathrm{c}}=1$, con lo cual las lecturas de la temperatura son directas. Para el termómetro de enfriamiento, también en el supuesto de que $k$ fuese constante, la solución sería $\quad T-T_{a m}=\left(T_{H}+T_{a m}\right)\left(\frac{T_{F} T_{m}}{T_{H} T_{T_{m}}}\right) \frac{t_{t_{p}}}{\text { torrespon- }}$ diendo los subíndices $H$ y $F$ a los puntos caliente y frío, o bien donde se inicia y termina el proceso. Por $T_{a m}$ indicamos la temperatura ambiente, parámetro necesario en el cálculo del enfriamiento; es obvio que cuando las temperaturas del cuerpo y ambiente sean iguales no habrá enfriamiento. Definiremos $\tau=\frac{t}{t_{F}}$ parámetro que representa la fracción del tiempo total transcurrido hasta llegar a la temperatura $T$, y que podemos entender como un tiempo adimensional. Es fácil ver que si los tiempos siguen una progresión aritmética, tal como una suma sucesiva de $\Delta t \mathrm{o} \Delta \tau$, la diferencia de temperatura $T-T_{a m}$ se multiplicará por un factor $\left(\frac{T_{F}-T_{a m}}{T_{H}-T_{a m}}\right)^{\Delta \tau}$, que es una progresión geométrica.

La ecuación anterior representa la evolución temporal del fenómeno. Pero, por otro lado, el carácter geométrico que indica Newton permite representar la temperatura por un índice $\gamma$, relacionado con $T$ por la ecuación $T=T_{F} B^{\gamma-1}$, donde $B$ es la base, que podría ser cualquier número real positivo, y para la que toma $B=2$. La relación entre $\gamma$ y $\tau$ se obtendría igualando esta ecuación con la anterior. Si introducimos el valor $\gamma_{H}$, que sería el del índice en el punto caliente, es decir, $T_{H}=T_{F}$ $2^{\gamma H-1}$, y $\eta=T_{a m} T_{F}$. tras los cálculos pertinentes se llega la siguiente expresión $\tau=\ln \frac{2^{\gamma-1-\eta}}{2^{\gamma H-1-\eta}} / l n \frac{1-\eta}{2^{\gamma H-1-\eta}}$. Es fácil comprobar los valores de $\tau$ en los dos puntos extremos: caliente $T=T_{H}, \gamma=\gamma_{H}, \tau=0$; punto frío $T=T_{F}, \gamma=1, \tau=1$. En el caso de que la temperatura ambiente fuese cero, $T_{a m}=0$, la expresión dada se transforma en una simple relación lineal $\gamma_{H}-\gamma=\left(\gamma_{H}-1\right) \tau$. En lo anterior se ha supuesto $\gamma_{H}$ como conocido; sin embargo, en el caso más general, para su determinación habría que hacer uso del solape de las dos escalas, la aritmética y la geométrica, utilizando para ello los datos de un punto de solapamiento con temperatura y tiempo conocidos, tal $T_{i} y \tau_{i} \mathrm{y}$, de los que se obtendría el correspondiente, que introducidos en la última fórmula arrojarían el valor de $\gamma_{H}$.

En el punto anterior hemos visto que Newton toma como punto $F$ la temperatura del cuerpo humano $(\gamma=1)$ y la cocina como punto caliente $\left(\gamma_{H}=5\right)$. Con ayuda de las ecuaciones obtenidas y con las temperaturas geométricas $\gamma$ dadas por Newton (Tabla I, columna 2a), hemos reconstruido los valores de $\tau$ correspondientes para cada estado en dos supuestos, uno con $T_{a m}=0 \mathrm{y}$ otro con $T_{a m}=15$ ${ }^{\circ} \mathrm{C}$. Los valores obtenidos se muestran en la Tabla I como

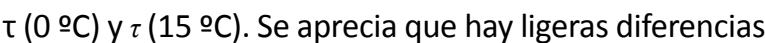
entre ellas. Imaginamos que las medidas que encontró Newton debieron de estar entre ambas.

\section{INSTRUMENTOS DE MEDIDA Y MODUS OPERANDI}

No tenemos datos sobre el termómetro de aceite de linaza de Newton que, además, posiblemente sea invención suya; sin embargo, disponemos de una descripción indirecta debida a John Theophilus Desaguliers, que expresamente dice: "Ya que menciono el termómetro de Sir Isaac Newton, creo que no será impropio dar cuenta de la forma de fabricarlo, pues hice una vez tres de ellos bajo la dirección de Sir Isaac"13. Consistía en un bulbo de dos pulgadas de diámetro [50,8 mm] acoplado a un tubo de tres pies de largo [903 $\mathrm{mm}$ ] y media pulgada de paso interior [12,7 mm] que tenía pegado un papel para marcar la escala. Para realizar las marcas utilizó una medida de mercurio $\left[\sim 3,3 \mathrm{~cm}^{3}\right]$ con la que rellenaba sucesivamente el conjunto; el bulbo tomó 21 medidas y al ascender el nivel por el tubo trazaba una marca por cada una; la separación resultante entre ellas era alrededor de una pulgada, de lo que estimamos que habría unas 36 . A continuación retiró el mercurio y lo llenó de aceite hasta la marca 10-12, colocó el bulbo en un crisol con arena y observó cómo ascendía, chisporroteaba y emitía humos blancos que interpretaba que servían para purificar el aceite. Ya con el instrumento listo relata la 
realización de cinco mediciones: ebullición del agua y cuatro fusiones. Estas eran, una mezcla no definida de plomo, estaño y bismuto; plomo y estaño a partes iguales; estaño; y plomo. Los resultados que presenta Desaguliers son en cierto grado consistentes con los datos actuales. No obstante, hay una salvedad importante: el coeficiente de dilatación del aceite, deducido a partir de los datos que proporciona, es unas seis veces más alto que los valores medidos hoy día ${ }^{14}$.

Además de lo anterior, Desaguliers nos aporta una información quizás más interesante aún. Se trata de una descripción del modus operandi para medir el punto de fusión de las aleaciones. Cuenta que dispuso varios crisoles en los que mantenía las diferentes aleaciones en estado líquido y otro con arena para el termómetro, que estaba más caliente que los demás. Después retiraba el crisol con la aleación a medir y lo colocaba en el suelo donde comenzaba a enfriarse. Entonces procedía: "Saqué el termómetro de su crisol de arena e introduje su bulbo en la mezcla y lo saqué inmediatamente, y esto varias veces hasta que la mezcla en enfriamiento formó una piel alrededor del bulbo del termómetro, y a esta [medida] llamaríamos el grado de calor capaz de fundir la mezcla"15. Es plausible que Newton usase la misma técnica. Desaguliers termina refiriéndose otra vez a Sir Isaac, "Él me dijo que su termómetro de aceite de linaza más general, para grados de calor bajos, empezaba en el punto de congelación y que la distancia entre este y la ebullición tenía 34 de sus divisiones. ${ }^{16 "}$

\section{Para establecer la escala, Newton nos dice}

Así pues, primeramente averigüé con el termómetro de aceite de linaza que si, cuando el termómetro se colocaba en nieve liquescente, el aceite ocupaba un espacio de 10000 partes, el mismo aceite dilatado por el calor de primer grado o del cuerpo humano ocupaba un espacio de 10256; y por el calor del agua a punto de empezar a hervir, un espacio de 10705; y por el calor del agua hirviendo impetuosamente, un espacio de 10725; y por el calor de estaño líquido ardiente cuando empieza a endurecerse y adquirir la consistencia de una amalgama, un espacio de 11516; y cuando endurece, un espacio de 11496.

Estos cinco valores se han colocado en la columna sexta de la Tabla I, indicados como Vol. Con ellos Newton nos está dando los puntos de tarado de la escala, en forma adimensional, al suponer que el volumen inicial es de 10000. Es una escala que toma como lineal, tal como afirma en el último párrafo del artículo:

Los calores así encontrados mantenían entre sí la misma relación que los calores hallados con el termó- metro y por tanto suponemos acertadamente que las dilataciones del aceite son proporcionales a sus calores.

Sin embargo, la dilatación del aceite de linaza no es constante. Esto está claro en el gráfico que proporciona Grigull, que se obtuvo en laboratorio midiendo la dilatación de dos tipos de ese aceite en varias condiciones ${ }^{17}$. Por otra parte, este autor comprueba que los valores presentados por Newton eran realistas. Para analizar la incidencia de la no linealidad en los resultados hay que entrar en el proceso de medida. En este, el bulbo se introduce en el medio caliente donde el aceite adquirirá la temperatura de la fuente de calor de forma progresiva a través del cristal por un movimiento convectivo interno. Durante el proceso de calentamiento una parte del aceite ascenderá por el tubo hasta alcanzar el valor final estacionario. Ahora bien, la temperatura tanto del tubo como la del aceite que lo llena será la del ambiente, diferente de la del bulbo. La transmisión del calor desde el bulbo hacia el tubo casi solo se realiza por el cristal externo, dado la baja conductividad del aceite. Según Grigull, el efecto del bulbo solo afecta a unos pocos centímetros del tubo. En definitiva, la masa inicial de aceite que estaba a temperatura cero sería $\rho_{o} V_{0}$, la cual se divide en una parte que permanece en el bulbo, pero con menor densidad, $\rho_{T} V_{0}$ y otra que asciende por el tubo, $\rho, S x$, siendo $S$ la sección del mismo y $x$ la altura. Es claro que $\rho_{o} V_{0}=\rho_{T} V_{0}+\rho_{a} S_{t} x$. Por otra parte, las densidades son proporcionales a los inversos de las dilataciones $\rho_{T}=k(1+\beta T)$, siendo el parámetro $\beta$ el coeficiente de dilatación medio entre el cero y la temperatura ${ }^{18}$ de lo que resulta la ecuación $\frac{1}{\left.1+\beta_{T} T\right)}=1-\frac{S x}{V^{0}(1+\beta a T a)}$ que relaciona las alturas con las temperaturas, $x(T){ }^{19}$ Aplicando estas fórmulas y tomando como referencia para el ajuste lineal el punto de ebullición del agua, los errores debidos a la no linealidad son de alrededor de 0,16 o $\mathrm{N}$ y $-0,66$ oN para el punto correspondiente al cuerpo humano (P.6) y el de fusión del estaño (P.16B $)^{20}$. Son más bien pequeñas desviaciones.

Pasemos ahora al termómetro de enfriamiento. Como hemos dicho era un tocho de hierro, en función de probeta, y un reloj utilizado como cronómetro. Los datos que nos proporciona Newton son más bien vagos. Escribe:

calenté un hierro bastante grueso hasta que estuviera bastante candente, y una vez sacado del fuego con tenazas también candentes, lo coloqué al instante en un lugar frío donde el viento soplaba constantemente y, poniendo sobre él partículas de diversos metales y otros cuerpos licuables, anoté los tiempos de enfriamiento hasta que todas las partículas endure- 
cían perdiendo la fluidez y el calor del hierro igualase el calor del cuerpo humano.

Fig. 1. Tocho probeta del termómetro de enfriamiento

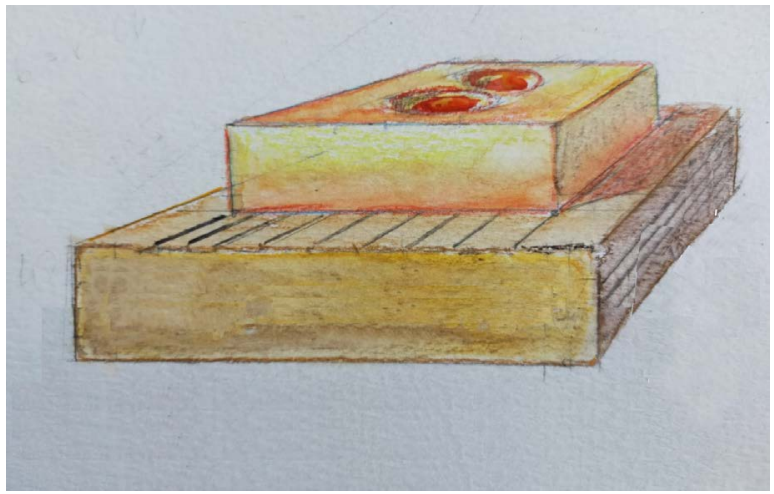

Realmente no es mucho. La única pista sobre las dimensiones de la probeta es el hecho de que era bastante gruesa y manejable con unas tenazas. Sobre la forma lo más plausible es que fuese paralelepipédica y que dispusiera de unos agujeros o receptáculos en la parte superior para recibir las muestras de metal a medir (Fig. 1). Estimamos que debería tener alrededor de una pulgada de grueso con un lado de dos y el otro de tres $(25 \times 50 \times 75$ $\mathrm{mm})$, y que pesaría algo más de libra y media $(0,68 \mathrm{~kg})$.

Imaginemos cómo debió de ser el modus operandi. Las operaciones se efectuaban en un cobertizo con salida a un patio donde corriese el aire. No todos los días eran propicios, se necesitaba viento. El proceso se iniciaba con el encendido de la cocina, alimentándola con hulla mientras el fuego ganaba en intensidad. Ya con el fuego activo, utilizando las tenazas, se colocaba la probeta entre las brasas, removiéndola mientras se calentaba lentamente apreciando el cambio progresivo de color hasta alcanzar un rojo vivo. Cuando ya estaba estable se la sacaba asida fuertemente con las tenazas, también rojas en sus mordazas y se llevaba al exterior, situándola sobre una pila de ladrillos o piedras, y dejándola expuesta a un vientecillo suave. Como él nos indica:

Coloqué el hierro no en aire tranquilo, sino en un viento que fluía uniformemente, para eliminar el aire calentado por el hierro, sustituyéndolo uniformemente por aire frío.

Casi sin perder tiempo, con otras tenazas se ponían las muestras de las aleaciones preparadas dentro de los receptáculos, que se licuarían casi de forma inmediata refulgiendo sobre rojo del hierro. El tiempo empezaba a correr; se miraba al reloj y se realizaba la primera anotación.
El color del hierro iba virando hacía el oscuro lentamente. Había que estar atento al endurecimiento de los metales, quizás agitando la probeta para cerciorarse. Según fuese la hora, crepúsculo o noche, también se podría anotar cuando el resplandor desaparecía. Así, uno tras otro el registro de tiempos crecía.

Cuando se estimaba que se acercaba al punto de ebullición del agua se iban dejando caer gotas sobre él. Las primeras hervirían y se volatizarían sin dejar rastro, hasta que una comenzaría a chisporrotear, pero quedaría ya parte de ella como líquido, esto sucedía sobre los 35 o 36 N. Claro que si el agua estaba fría esto sucedía un poco antes, a los 37 oN. Un poco más tarde podría ser el momento de colocar sobre la probeta un termómetro de aceite, que estaba preparado en un baño caliente, y después esperar a que llegase a los 12 oN del cuerpo humano para hacer la anotación final.

Todo el proceso duraba varias horas, pero tras un breve descanso había que repetir y quizás varias veces. Antes había que retirar los restos de los metales y limpiar la cascarilla de la oxidación. Calentar otra vez, probar otro grupo de metales y seguir. Había que aprovechar el día, desde el amanecer hasta el anochecer e incluso la noche, pues los cuerpos ardientes permanecían más tiempo refulgiendo en la oscuridad y eso había que anotarlo.

Tras días de pruebas, Newton trataría de poner orden en sus medidas, lo que hoy se denomina reducción de datos. Para cada punto tendría varios tiempos, muy probablemente habría que eliminar algunos por ser claramente discordantes, y al final estimar entre todos uno como definitivo para cada temperatura. Después, manejando sus propios métodos de cálculo y utilizando los tiempos para las temperaturas ya obtenidas con el termómetro de aceite (citamos como ejemplo los P.12 y P.14), hallaría el calor geométrico de la cocina y luego todos los demás. Con estos, las temperaturas aritméticas (del P.17 a P.22) "se pueden encontrar fácilmente por la tabla de logaritmos". Nuestras fórmulas equivalentes son $\gamma=5-4 \tau$ y y $\mathrm{T}=12 \cdot 2^{\gamma-1}$.

\section{CORRELACIONES}

Hasta aquí llega el trabajo de Newton. Ahora busquemos la correlación entre sus valores en grados oN y sus equivalentes en Celsius. Contamos para ello con puntos reproducibles, que son la ebullición del agua, fusión de los metales estaño, bismuto, plomo y antimonio, y doce aleaciones, todos marcados con un asterisco en la primera columna de la Tabla I. Para el estaño (P.16B) y el plomo (P.18) Newton muestra una imprecisión similar 
TABLA II. FUSIÓN DE ALEACIONES

\begin{tabular}{|c|c|c|c|c|c|c|}
\hline & $\mathrm{Pb}$ & Sn & $\mathbf{B i}$ & $\mathrm{Sb}$ & $T(O N)$ & $\mathrm{T}(\mathrm{o} C)$ \\
\hline 12 & 2 & 3 & 5 & & 34 & $98-112$ \\
\hline 13 & 1 & 4 & 5 & & 40 & 125 \\
\hline 14 & & 1 & 1 & & 48 & $138-155$ \\
\hline 15 & & 2 & 1 & & 57 & $138-186$ \\
\hline 15 & 2 & 3 & & & 57 & 183-185 \\
\hline 15 & & 5 & 2 & & 57 & $138-193$ \\
\hline 15 & 1 & & 1 & & 57 & $124-142$ \\
\hline 16 & & 8 & 1 & & 68 & $171-216$ \\
\hline $16 \mathrm{~A}$ & & 1 & & & 70 & 232 \\
\hline 17 & & & 1 & & 81 & 271 \\
\hline 17 & 4 & 1 & & & 81 & $183-286$ \\
\hline 17 & 5 & 1 & & & 81 & 167-291 \\
\hline 18 & 1 & & & & 96 & 327 \\
\hline 19 & & 1 & & 1 & 114 & $354-426$ \\
\hline 19 & & & 7 & 4 & 114 & $331-467$ \\
\hline 20 & & & 1 & 2 & 136 & $420-570$ \\
\hline 20 & & 1 & & 5 & 136 & $425-576$ \\
\hline $20 \mathrm{~A}$ & & & & 1 & 146 & 631 \\
\hline
\end{tabular}

a la ya citada con el agua, que no se repite en ninguna de las aleaciones, lo cual no deja de ser sorprendente, ya que estas, a diferencia de los metales puros, no tienen un punto de fusión fijo.

Una aleación es una mezcla de dos o más elementos metálicos en estado puro, aunque también pueden contener elementos no metálicos. Los constituyentes de una aleación no generan enlaces químicos entre ellos, sino que forman microestructuras cristalinas dependiendo de las proporciones y de la temperatura. Esto se refleja en un gráfico, denominado diagrama de fases, que muestra los dominios de cada microconstituyente, las temperaturas de transición entre ellos, y si están en fase líquida, sólida o si coexisten ambas. El resultado es que para cualquier proporción de sus componentes hay un rango de temperaturas en que coexisten las fases sólida y líquida. Únicamente en ciertas proporciones, denominadas eutécticas, se comportan como un metal puro. Con ayuda de estos diagramas hemos hallado las temperaturas a la que se inicia y termina la fusión de las aleaciones utilizadas por Newton. Para el caso de aleaciones ternarias el proceso es similar pero más complejo. Ambas temperaturas se presentan en la última columna Tabla ${ }{ }^{21}$, que además también se han trasladado a la columna séptima de la Tabla I, indicándolas como $T_{R}$.

Con estas aclaraciones, la pregunta que nos cabe hacer es qué temperatura encontraba Newton en sus mediciones. Dado que se trataba de un proceso de enfriamiento, las aleaciones estarían en estado líquido sobre la placa caliente, por lo que suponemos que detectaría los primeros estadios de la solidificación, es decir la más alta. De todas formas, la apreciación visual de este hecho no le debió de resultar fácil. Más adelante, cuando nos refiramos a las temperaturas de referencia, consideraremos las máximas.

La correlación entre las temperaturas encontradas por Newton para los estados que hemos considerado característicos (columna 2a de la Tabla I) y sus valores de referencia (la 7ạ de la misma tabla) se presenta en la Fig. 2 , identificando para cada uno el punto correspondiente. Para cada aleación se han marcado la temperatura a la que se inicia y termina la fusión, aunque indicadas con símbolos diferentes. También se muestran los puntos 12 oN y 72 oN que, como ya hemos dicho, indican la temperatura corporal y el límite superior del termómetro de 
Fig. 2. Relación entre las temperaturas de Newton y las de referencia

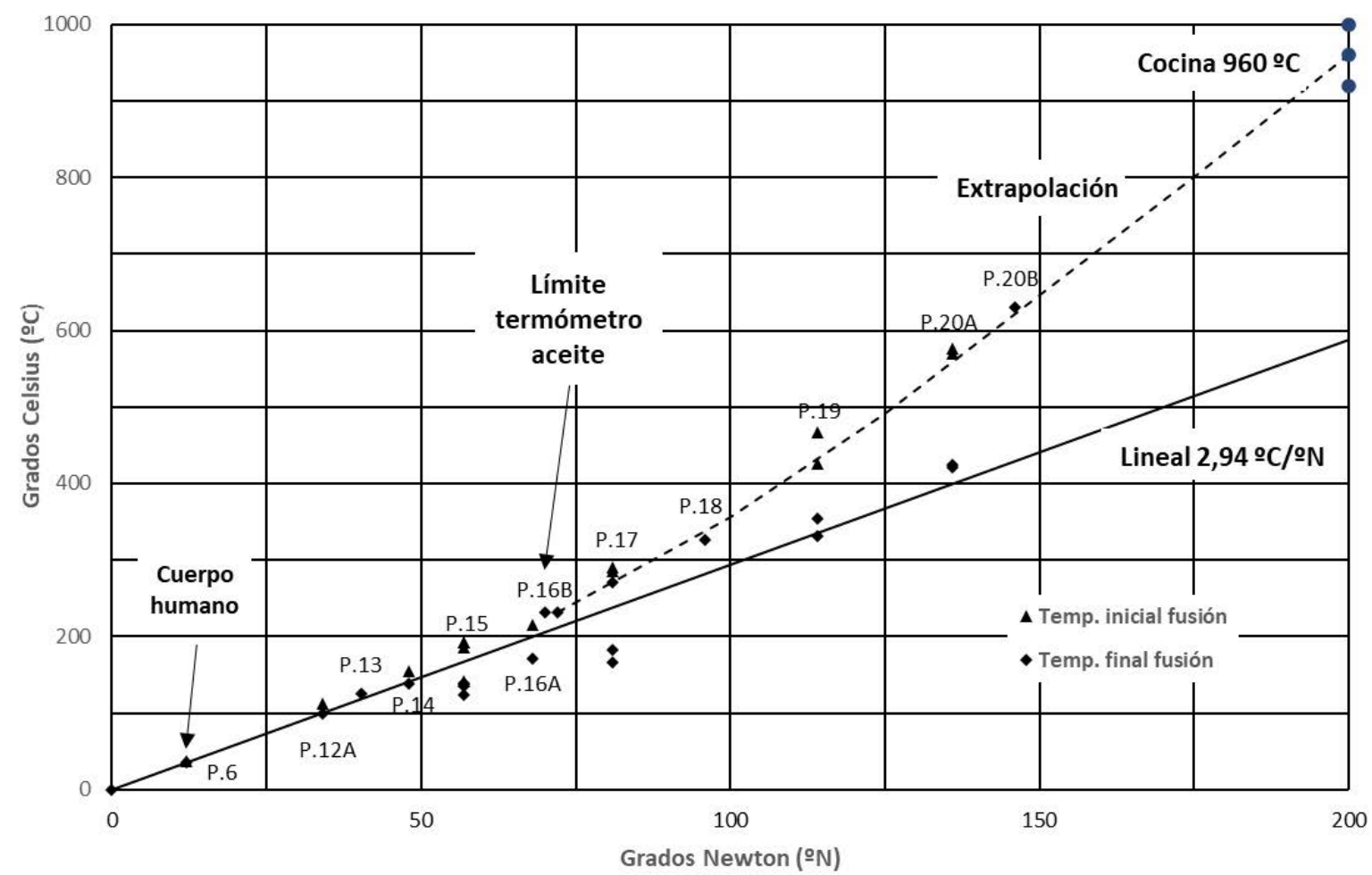

aceite de linaza. Se ha trazado la recta de correlación lineal entre los ${ }^{\mathrm{O}} \mathrm{N}$ y los ${ }^{\circ} \mathrm{C}$, para lo que se ha tomado como referencia la ebullición del agua, de lo que resulta 2,94 응N (100/34). Se aprecia claramente que para temperaturas bajas hay una buena correlación, que se pierde cuando la temperatura aumenta. Ello indica que la probeta se enfriaba más de lo que Newton pensaba. Se completa la figura con una extrapolación a sentimiento, que sigue las temperaturas de inicio de fusión de las aleaciones, llegándose a 960 드, con un margen estimado de $\pm 40 \stackrel{\circ}{\circ}$, para los 200 N.

\section{SIMULACIONES}

Fig. 3. Enfriamiento por convección

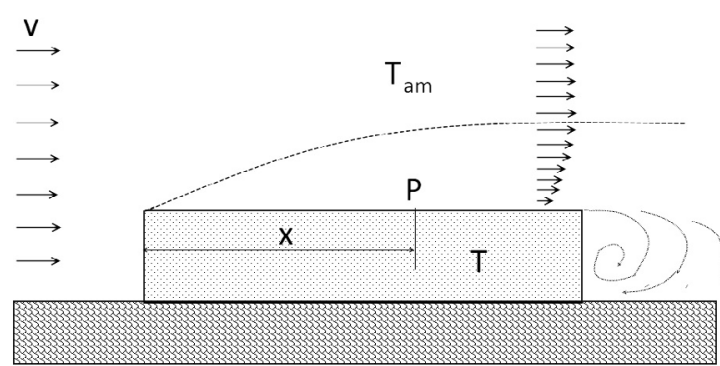

Para acometer una simulación se precisa un modelo físico definido y las leyes que regulan su comportamiento. Es obvio que cualquier simulación es siempre una aproximación a la realidad y que tanto mejor será cuanto lo sea su modelo y las leyes regulatorias. En nuestro caso la simulación será imperfecta dado que se basará en conjeturas; no obstante, se pondrá de manifiesto cómo ese enfriamiento adicional afectó a las medidas de Newton.

El que la placa se enfriase más rápidamente no significa que la ley de Newton no se cumpliera, sino que había un enfriamiento adicional que, como hemos dicho anteriormente, era la radiación térmica que sigue la ley de Stefan-Boltzmann, descubierta casi dos siglos después, y que establece que la emisión de un cuerpo negro, o radiador ideal, es proporcional a la cuarta potencia de la temperatura, esto es $E=\sigma T^{4}$; siendo $T$ la temperatura absoluta ${ }^{22}$. Para un cuerpo en concreto, que no goza de la propiedad de ser negro, hay que introducir un factor de emisividad, $\varepsilon$, siempre menor que la unidad.

El modelo físico del sistema se presenta en la Fig. 3. La probeta caliente está colocada sobre un ladrillo $u$ 
otra base y sometida a una corriente de aire con velocidad $v$. Es un fenómeno de enfriamiento por convección forzada cuyo análisis entra dentro del dominio de la aerotermodinámica. La corriente de aire originará una capa límite cuyo origen está en el borde delantero de la probeta y que baña todo el cuerpo. Es dentro de esta capa donde se produce el intercambio térmico. En un punto de la superficie existirá un flujo local de calor que se rige por la ecuación $\dot{q}=h(T-T)$, donde $h$ es el coeficiente de transmisión y $T_{r}$ una temperatura denominada de recuperación, que a las velocidades en que nos estamos moviendo es prácticamente igual a la del ambiente exterior, $T_{a m}$. En esta fórmula, la temperatura $T$ es, estrictamente, la temperatura superficial, que, además, sería función de $x$; sin embargo, supondremos que el bloque mantiene una temperatura uniforme. Vemos que el flujo de calor es una aplicación de la ley de Newton. Para la determinación de, entran en juego tres números adimensionales: el de Nusselt, el de Reynolds y el de Prandtl, cuyas definiciones son $N u=\frac{h x}{k} \operatorname{Re}=\frac{p v x}{\mu} \operatorname{Pr}=\frac{c p \mu}{k}, \mathrm{y}$ que no son independientes entre sí. Ade ${ }^{\mu}$ ás de $, h, v$, y $x$, ya definidos o explicitado en la figura, el resto de los parámetros son:, la transmisión de calor; $\rho$, la densidad; $\mu$, la viscosidad; y $c_{p}$ el calor específico a presión constante, todos ellos para el aire ${ }^{23}$.

El régimen dentro de la capa límite puede ser laminar o turbulento según el valor del $R e$. Para valores inferiores a $5 \cdot 10^{5}$, que es con mucho nuestro caso, será del primer tipo. En este régimen los tres números adimensionales se vinculan por la llamada correlación de Pohlhausen: $N u_{x}=0,332 \cdot \operatorname{Re}_{x}^{1 / 2} \operatorname{Pr}^{1 / 3}$, la cual permite calcular el valor de local en el punto, y consecuentemente $\dot{q}(x)$ que integrado a lo largo de la placa nos daría el calor total $\dot{Q}_{c}$. Sin embargo, el problema se simplifica utilizando valores medios, que consideramos que para este caso está justificado. En tal caso la anterior correlación toma la forma de $\overline{\bar{N}} u_{x}=0,664 \operatorname{Re}_{x}^{1 / 2} \operatorname{Pr}^{1 / 3}$, aplicado el valor del a toda la longitud de la placa obteniéndose $\bar{h}$. El resultado es que el flujo de calor por convección será $Q_{c}=\bar{h}\left(T-T_{a m}\right) S_{B^{\prime}}$, siendo $S_{B}$ la superficie del cuerpo bañada por la corriente de aire, que será la superficie superior y las dos laterales de la probeta. Quedarían fuera la parte frontal, donde hay una zona de remanso, y la trasera, dentro de la estela turbulenta generada en el borde trasero. En una y otra hay flujo de calor, pero no tenemos herramientas para su cálculo; sin embargo, como una aproximación, supondremos que ambas son equivalentes a una superficie adicional que se añade a la bañada.

La otra fuente de enfriamiento es la radiación térmica que se emite desde toda la superficie y cuyo valor será $\dot{Q}_{e}=\varepsilon \sigma S_{E} T^{4}$. Siendo la constante universal de
Stefan-Boltzmann, ${ }^{24}$ la emisividad propia del material y $S_{E}$ la superficie radiante, que será toda la exterior del paralelepípedo. Ahora bien, el cuerpo además de emitir también absorberá radiación del exterior, tal que llegaría a un equilibrio térmico cuando su temperatura alcanzase la del ambiente. Es decir, la última ecuación se convertirá en $\dot{Q}_{e}=\varepsilon \sigma S_{E} T^{4}-\varepsilon \sigma S_{E} T_{\text {am }}^{4}$. Los datos de que disponemos para la emisividad del hierro son bastante dispares: 0,24 para el esmerilado; 0,14-0,38 para el pulido; 0,87-0,95 para el laminado y 0,69 para el oxidado, además de intervenir también la temperatura.

Finalmente, queda por dilucidar qué sucede en la superficie de contacto inferior con un supuesto ladrillo o bloque de piedra. Habrá un flujo de calor de muy difícil determinación, pues se cruzarán las emisiones térmicas en ambos sentidos más la transmisión directa por el contacto. A falta de una hipótesis razonable hemos preferido suponer que no hay transmisión alguna, aunque al final realizaremos algunas consideraciones al respecto.

Como ya hemos advertido, supondremos que en cada instante la probeta tiene una temperatura uniforme, lo cual es verosímil pues la trasmisión interna es más rápida, dado el alto valor del coeficiente de transmisión térmica del hierro. Por tanto, la ecuación que regula su pérdida de calor será , donde es la densidad, el calor específico y el volumen ${ }^{25}$. En resumen, como ecuación final tenemos:

$$
\frac{d T}{d t}=-\frac{h S_{B}}{V \rho_{h} c_{h}}\left(T-T_{a m}\right)-\frac{\varepsilon \sigma S_{E}}{V \rho_{h} c_{h}} T^{4}+\frac{\varepsilon \sigma S_{E}}{V \rho_{h} c_{h}} T_{a m}^{4}
$$

Ecuación diferencial que tiene solución analítica por ser reducible a la integral de una función racional de cuarto grado. Para obtener esa solución habría primero que encontrar las cuatro raíces del polinomio, cuestión ardua, y luego descomponerlo en fracciones simples, cuestión tediosa. Con estos inconvenientes hemos preferido integrarla numéricamente con las condiciones iniciales de $T=T_{H}$ para $t=0$. La solución será una función $T(t)$, en la que determinaremos por interpolación el instante $t_{F}$ en que la temperatura llega a la del cuerpo humano, tal $T_{F}=T\left(t_{F}\right)$. El intervalo de validez $\left[0, t_{F}\right]$ se adimensionaliza a $[0,1]$ con $\tau=t t_{F}$, quedando la solución como $T(\tau)$.

Para realizar el cálculo tomaremos la probeta con unas dimensiones de $7,5 \times 5 \times 2,5 \mathrm{~cm}$, como hemos supuesto en el modus operandi. Más difícil nos es conjeturar la velocidad del viento, tomaremos como base $2,5 \mathrm{~m} / \mathrm{s}$ y después probaremos con $5 \mathrm{~m} / \mathrm{s}^{26}$. Tampoco tenemos un valor claro para la emisividad, así que uti- 
lizaremos 0,25 y 0,5 . Y, por último, las dudas persisten en cuanto a la temperatura ambiente, que si bien tiene un efecto casi insignificante a temperaturas altas, no sucede lo mismo al acercarse al final del proceso. Es fácil ver que es muy diferente que estemos en un día de invierno, esto es con un ambiente cercano a los 0 oC, o en uno de verano, que estaríamos sobre los 18 oC; en el primer caso la diferencia con el cuerpo humano sería de 36 으 f frente a los 18 ㅇ C del segundo: el doble. Ello implica un enfriamiento bastante más lento al final. Que Newton no era ajeno a este problema lo encontramos cuando expone:

Suponiendo luego que los excesos de los calores del hierro y de las partículas en solidificación por encima del calor de la atmósfera, halladas con el termómetro, están en progresión geométrica mientras que los tiempos están en progresión aritmética, se determinaron todos los calores.

Ese calor de la atmósfera es lo que llamamos temperatura ambiente. El hecho de que esta pueda variar indica que las medidas solo son repetibles para valores iguales. Consideremos los casos de 0 y 15 으, interpretados como correspondientes a invierno y verano, a tenor

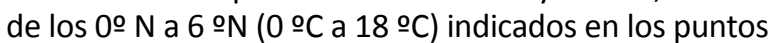
P.2-P.4 de la Tabla I".
En resumen, para nuestra simulación tenemos varios parámetros inciertos, de los cuales hay tres significativos: la emisividad del hierro, la velocidad del viento y la temperatura ambiente. Otros, como la temperatura de la cocina o las dimensiones de la probeta anticipamos que no cuentan tanto en los resultados finales como en un principio pudiera parecer. Ya hemos indicado que tomaremos dos valores para cada parámetro, lo cual nos lleva a ocho simulaciones, que agruparemos en dos series tomando la temperatura ambiente como parámetro principal. Como hemos explicado, en cada caso obtendremos una función $T=T_{k}(\tau)$ y el tiempo total. Como temperatura inicial se han tomado los 960 으 a que se llegó en la extrapolación expuesta en la Fig. 2. Los resultados se presentarán en dos gráficos, uno para temperatura con cuatro curvas cada uno.

Para poder comparar los resultados de las simulaciones, se han marcado sobre los gráficos los valores obtenidos por Newton (columna 2 2 a de la Tabla I), convertidos de grados oN a Celsius, aplicando el factor 2,94 드을 ${ }^{27}$, e indicados como "Temperaturas Newton", en función de los tiempos adimensionales $\tau$

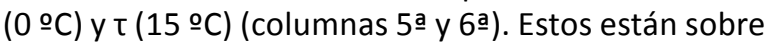
la curva que resultaría de aplicar la ecuación general con emisividad nula y con una temperatura de la cocina de 560 드, y que se representa en línea de trazos

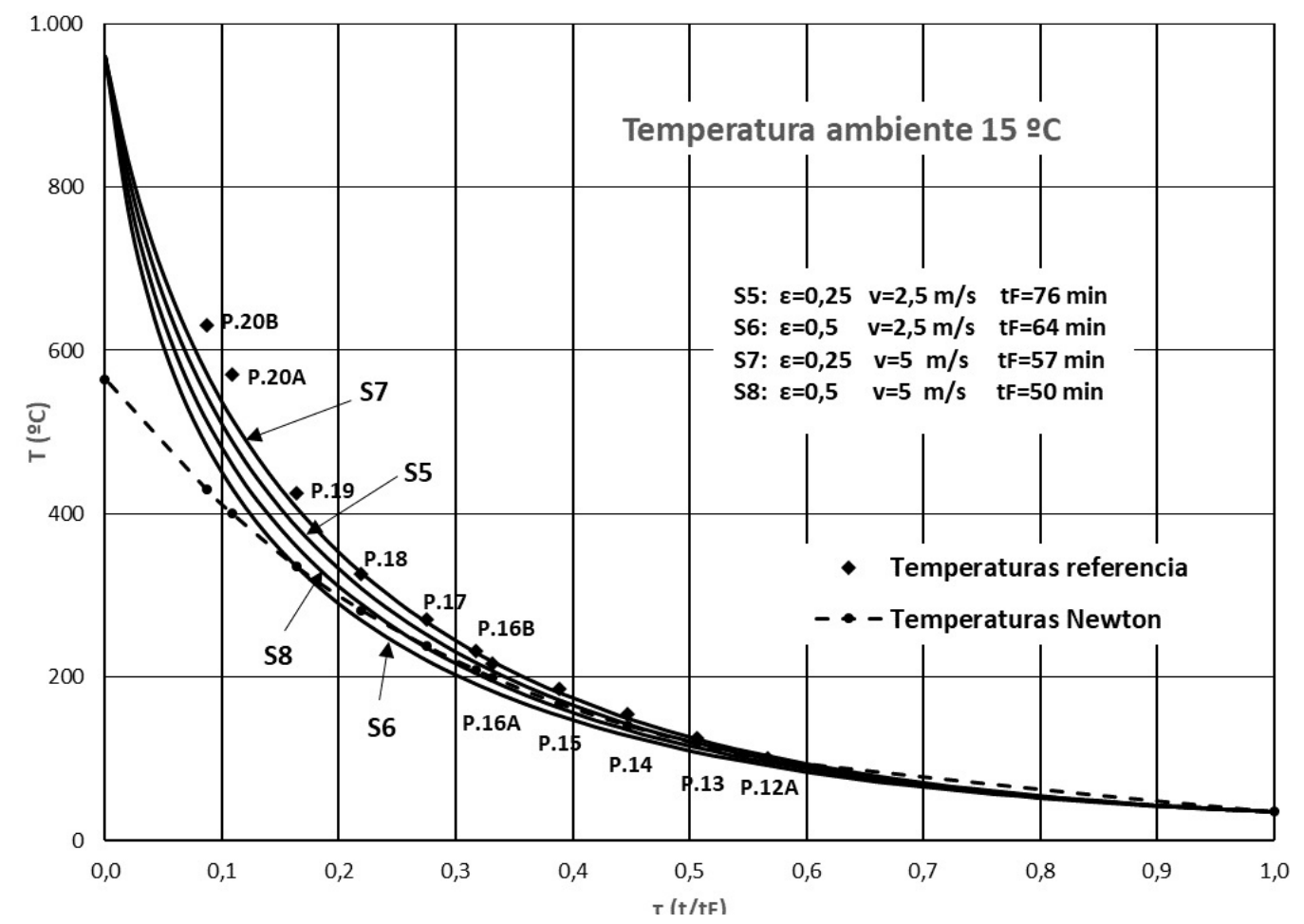

Fig. 4. Simulación. Temperatura ambiente fría 


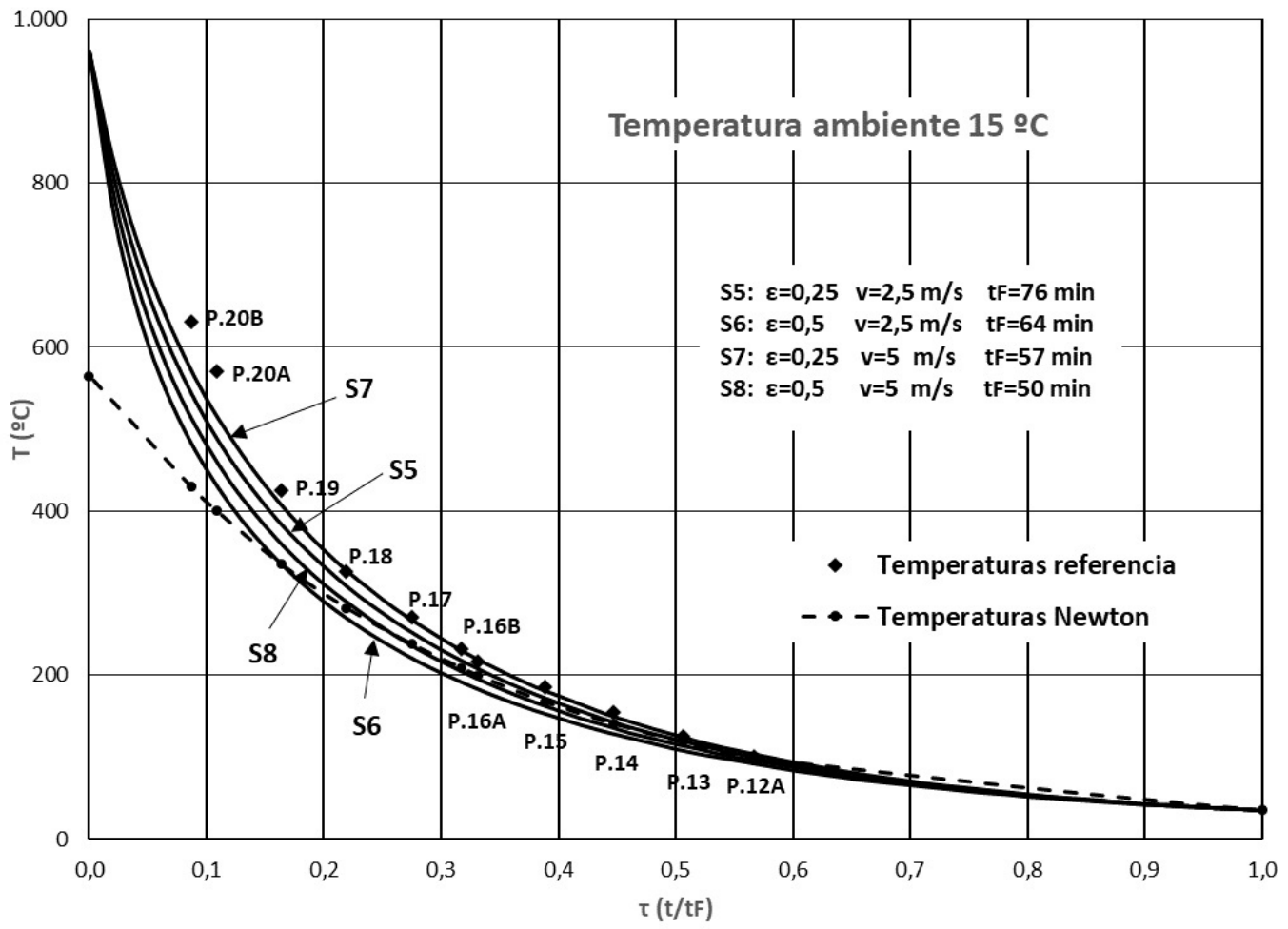

Fig. 5. Simulación. Temperatura ambiente cálida

en los gráficos. Asimismo, también se han marcado en estos las temperaturas de referencia (máximos de la columna 7ạ), junto con la indicación del punto a que se corresponden (columna 1a ), también en función de los correspondientes valores de $\tau$.

En la Fig. 4 se muestran los resultados para $T_{a m}=0$, que se interpreta como situación fría. De los cuatro casos, podemos considerar al primero $S_{1}$, con una emisividad $\varepsilon=0,25$ y una velocidad del viento $v=2,5 \mathrm{~m} / \mathrm{s}$, como el de enfriamiento más suave; mientras que el sería el de enfriamiento fuerte, con $\varepsilon=0,5$ y $v=5 \mathrm{~m} / \mathrm{s}$. Esto queda patente con los tiempos de enfriamiento van en consonancia con lo dicho, reduciéndose de los $t_{F}=64$ minutos del $S_{1}$ a 42 minutos para el $S_{4}$. De los otros dos, se enfría antes el $S_{3}$ que el $S_{2}$, lo que da a entender que cuenta más en el proceso la velocidad del viento que la emisividad, lo cual puede explicarse en que esta es muy activa a altas temperaturas, pero su efecto decrece rápidamente, mientras que el enfriamiento debido a la convección se mantiene durante todo el proceso. Aparte de estas consideraciones, visualmente se aprecia que la curva que más se aproxima a las temperaturas de referencia es la, seguida por la $S_{3}$. La diferencia que separa a los puntos P.20B y P.20A de es de unos $55^{\circ} \mathrm{C}$, que se eleva a 150 ㅇ C respecto a la $S_{4}$.
Pasemos ahora a la temperatura de 15 으 cuyas cuatro simulaciones están representadas en la Fig. 5. Lo primero que destacamos es que los tiempos del proceso se incrementan, desde 12 minutos en el caso $S_{5}$ frente al $S_{1}$ a 8 entre los $S_{8}$ y $S_{4}$. Además, se observa que tanto las temperaturas de referencia como las de Newton se han desplazado hacia la izquierda, debido a las diferencias de $\tau$ para 0 y $15 \stackrel{\circ}{ } \mathrm{C}$. Esto se debe a que el efecto de una mayor temperatura ambiente es casi nulo cuando el hierro está caliente, pero que se hace mucho más significativo al final. Así, los tiempos absolutos invertidos hasta que la temperatura descienda hasta 100 C en los casos $S_{1}$ y $S_{5}$, son 40,4 y 42,9 minutos respectivamente, una diferencia de 1,5 frente a los antedichos 12 del total. Observamos que la curva que se más se aproxima es la $S_{7}$ que es la correlativa a la $S_{3}$ del gráfico anterior, pero esa correlación no se cumple con la más alejada, ahora la $S_{6}$.

En estas dos figuras la calidad de la simulación se mediría por la aproximación de las curvas obtenidas a los puntos de referencia, que, a su vez, son los utilizados por Newton en su Scala. Una forma más directa de visualizar esa calidad sería simular además el modus operandi de Newton. Este, como hemos explicado, anotaba los tiempos que tardaba la probeta en alcanzar las temperaturas 


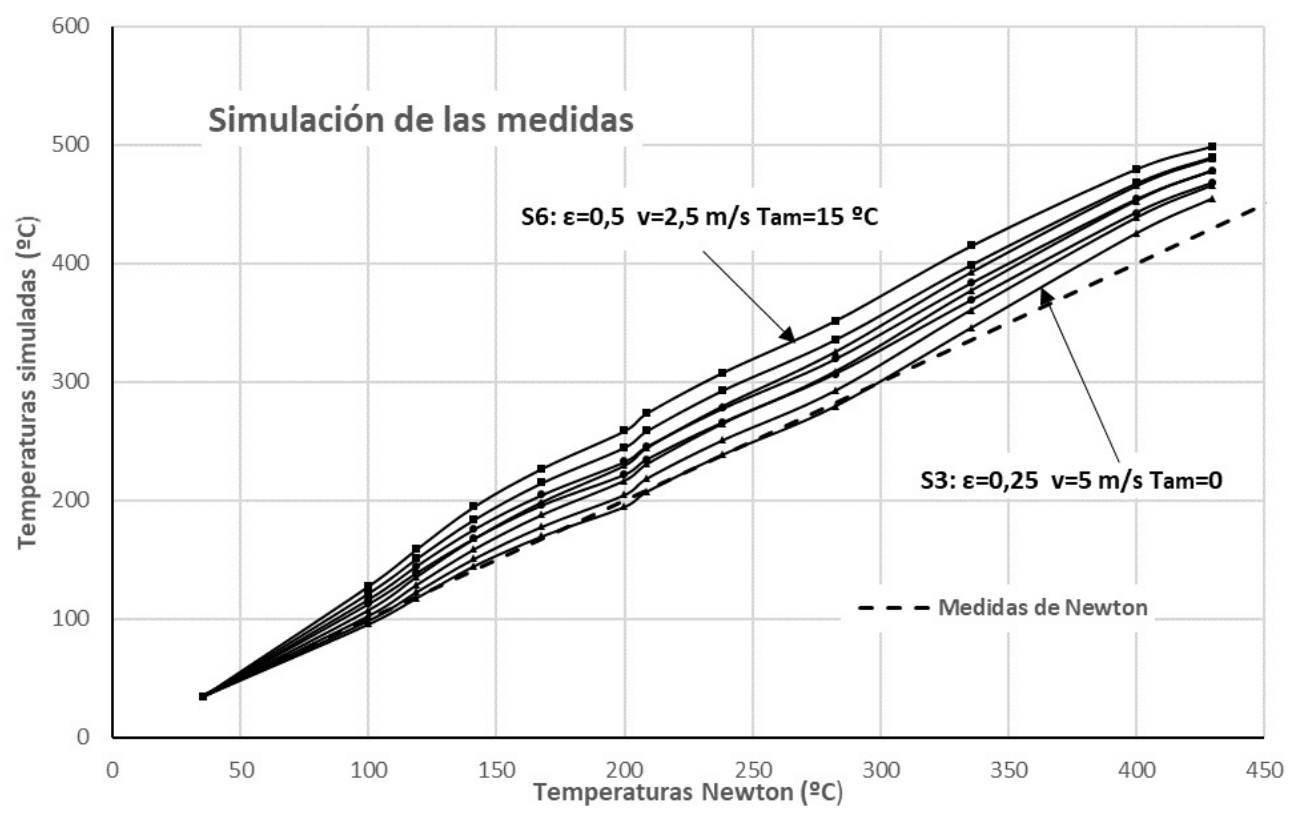

Fig. 6. Simulación de las medidas

de referencia y luego el tiempo total. Esa anotación la simularemos introduciendo en cada curva los valores de las temperaturas de referencia $T_{R}$ para obtener los $\tau i$ correspondientes, tal $T_{R i}=\mathrm{T}_{\mathrm{k}}\left(\tau_{\mathrm{i}}\right)$. Puesto que la tabla $\left[T_{R}\right]$ tiene 12 elementos tendremos 12 valores de $\tau$ para cada caso. Newton con sus tiempos reducidos procedía a calcular las temperaturas geométricas. Nosotros calcularemos los $\gamma$ por la fórmula $\gamma_{i}=5-4 \tau_{i}$. Finalmente, Newton encontraría las temperaturas aritméticas con ayuda de "la tabla de logaritmos". Aquí, emplearemos para ello la expresión $T_{S i}=T_{F} 2^{\gamma i-1}$, donde $T_{S i}$ son las temperaturas simuladas y $T_{F}$ la del cuerpo humano. Las ocho tandas de $T_{S}$ se representan en la Fig. 6 en las que se aprecia claramente la relación entre las medidas que obtuvo Newton y las simuladas. Se pone de manifiesto que cualitativamente la mejor es la $S_{3}$ y la peor la $S_{6}$. Una forma de cuantificar las diferencias de calidad sería introducir una figura de mérito que, a modo tentativo, definimos como la media de las diferencias cuadráticas ${ }^{28}$ de los 12 puntos. Con este criterio resulta un mérito de 128 para la mejor y 3668 para la peor.

El proceso de la conversión de las temperaturas geométricas a las aritméticas tenía como base, o vértice, la temperatura del cuerpo humano; o dicho con más rigor, el instante en que Newton estimaba que el hierro alcanzaba esa temperatura para detener el proceso y medir el tiempo total. La simulación es una buena herramienta para evaluar cómo influye una variación en la determinación de ese punto final; esto se hará suponiendo un error, o tolerancia, en la temperatura del cuerpo y comparando los resultados. Como referencia, tomaremos el caso $S_{3}$, y aplicaremos una variación de \pm 1 oN, casi $\pm 3 \stackrel{\circ}{\circ}$, a la $T_{F}=12$ oN. Obviamente los tiempos totales cambian, pasando de los 48,4 minutos a 47,0 y 49,8 , es decir una diferencia de 1,4 minutos en ambos casos. Sin embargo, en las temperaturas resultantes en uno u otro apenas hay variación respeto a la de referencia; las diferencias obtenidas no sobrepasan los 4 ㄷ en ningún punto de la escala, siendo menores para los valores altos. Si tomamos el factor de mérito, este sube a 185 para el caso negativo y baja a 122 en el positivo. Concluimos que el que Newton cortase el proceso un poco antes o después, por las razones que fuesen, no tenía mucha influencia en sus resultados.

Como último paso se han introducido algunas variaciones adicionales en el proceso y elementos. Primero en la temperatura de la cocina, que tanto si se eleva o se disminuye 50 ㅇ $\mathrm{C}$ no produce efectos sensibles. Otra variante es cambiar el tamaño de la placa probeta. Si se alarga hasta $10 \mathrm{~cm}$, tampoco hay cambios notables. Lo único que queda pendiente de evaluar es la transmisión de calor por la parte inferior, que hemos supuesto nula. En realidad, habrá emisión por esta superficie y también transmisión por contacto. Es plausible que la placa se colocase sobre un ladrillo o piedra de mayor tamaño; sea un caso u otro el coeficiente de transmisión calorí- 
fica interior de estos materiales es bajo, esto es, habría un calentamiento lento del soporte. Sea por ejemplo un bloque de granito de $20 \times 20 \times 10 \mathrm{~cm}$ con unos $10 \mathrm{~kg}$ de masa; si solo hubiera transmisión de calor por emisión el efecto final sería incrementar la temperatura de ese bloque en unos 2,5 우 ; si la masa es la mitad, ascendería al doble. Imaginemos que la temperatura llegase a cuatro veces, pues bien, en el efecto combinado apenas sería muy poco significativo, lo más en acortar unos 4 minutos el tiempo de enfriamiento.

Resumiendo. Los resultados de las simulaciones son bastante aceptables, incluso a pesar de las incertidumbres del proceso y materiales usados. Además, los resultados que se muestran Fig. 6 nos inducen a suponer que el hierro utilizado tenía baja emisividad, que el viento era más bien moderado y que el ambiente era frío. No obstante, estas conclusiones hay que tomarlas con cautela.

\section{LA LEY DE NEWTON}

Para concluir, daremos un repaso a la definición de la ley que tanto ha dado que hablar. Lo que podría ser su definición está en el siguiente párrafo:

Con el termómetro hallé la medida de todos los calores hasta el que funde el estaño, y con el hierro caliente hallé el resto de las medidas. En efecto, el calor que el hierro caliente comunica a los cuerpos fríos contiguos a él tras un tiempo dado, esto es, el calor que el hierro pierde en un tiempo dado, es como el calor de todo el hierro. Por tanto, si se toman tiempos de enfriamiento iguales, los calores estarán en razón geométrica, y por ello se pueden encontrar fácilmente por la tabla de logaritmos.

Y más precisamente de la siguiente oración: "el calor que el hierro caliente comunica a los cuerpos fríos contiguos a él tras un tiempo dado, esto es, el calor que el hierro pierde en un tiempo dado, es como el calor de todo el hierro" 29 .

Estimamos que se trata de una definición de la ley en forma integral. En nuestra argumentación comenzamos por dos hechos previos:

- El hierro se calienta a una temperatura $T_{H}$, la cocina, y se deja enfriar hasta llegar a una temperatura final $T_{F}$, cuerpo humano; proceso que transcurre en un tiempo $t_{F}$.

- Los conceptos de temperatura y cantidad de calor son distintos para nosotros, mientras que Newton empleaba ambos sin diferenciar. Así, al enfriarse, el hierro pierde tanto cantidad de calor como temperatura, ambas son indistintas pues la primera es proporcional a la segunda; pero al decir "el calor de todo el hierro" se ha de interpretar como cantidad de calor, aunque se exprese como la temperatura de la cocina $T_{H}$.

Luego, en el texto de Newton tenemos tres proposiciones:

$\mathbf{P}_{1}$ : "el calor que el hierro caliente comunica a los cuerpos fríos contiguos a él tras un tiempo dado". Esto lo interpretamos como el tiempo $t$ que el hierro caliente tarda en descender desde la temperatura $T_{H}$ hasta "comunicarse", esto es, igualar la de otro cuerpo, $T_{R^{\prime}}$ que se toma como una referencia. Matemáticamente significa que existe una función $T_{R}=T_{H}-T(t)$, donde $T(t)$ expresa la temperatura que se pierde desde el inicio.

$\mathbf{P}_{\mathbf{2}}$ : "el calor que el hierro pierde en un tiempo dado". Esta pérdida sería cantidad de calor, contabilizado entre el que había al inicio y el que queda tras un tiempo dado. Ahora bien, según lo expuesto en la proposición anterior, el calor que pierde en el tiempo $t$ será $\Delta T=\int_{0}^{\mathrm{t}} T d t^{\prime \prime}$. En términos actuales deberíamos escribir $\Delta Q=\int_{0}^{t} c_{e} T d t$ introduciendo el calor específico $c_{e}$.

$\mathbf{P}_{3}$ : "el calor de todo el hierro". Aquí es muy claro que se trata de cantidad de calor, no tiene ningún sentido la temperatura de todo el hierro. El calor de todo el hierro es toda la cantidad que éste pierde desde el inicio hasta la temperatura final, $t_{F}$, que sería $\Delta T_{F}=\int_{0}^{\mathrm{t} F}$ $c_{e} T d t$, o bien que $\Delta Q_{F}=\int_{0}{ }_{0}^{\mathrm{F}} c_{e} T d t$.

La relación entre las tres la entendemos matemáticamente como: $\mathrm{P} 1 \propto(\mathrm{P} 2 / \mathrm{P} 3)$, e introduciendo los valores físicos hallados. se convierte en:

$$
T_{H}-T(t)=T_{F} \frac{\Delta T}{\Delta T_{F}}=T_{F} \frac{\int_{0}^{t} T d t}{\int_{0}^{t_{F}} T d t}
$$

Que expresa la ley en forma integral. Para un intervalo corto entre $t$ y $t+\Delta t$ y la expresión anterior tomaría la forma: $\Delta T=-k T \Delta t$, donde el valor de la nueva constante es claro. Esta formulación se compagina con su aseveración de que a incrementos de tiempos en progresión aritmética los calores crecen en razón geométrica, ya que para cada $\Delta t$, los $\Delta t$ de la temperatura lo hacen proporcionalmente con $T$, no uniformemente. El límite, cuando $\Delta t \rightarrow 0$, conduce $a d T=-k T d t$, o bien, $\dot{T}=-k T$, que es como se formula habitualmente la ley.

Sobre el origen de la ley, nos inclinamos por la ya citada opinión de Ruffner, que conjetura que Newton la concibió antes de 1687, cuando estaba inmerso en experimentos químicos y en la determinación de puntos de fusión para lo que contaba solo con 
termómetros de alcohol, claramente insuficientes, y por lo que es plausible que sustituyese el alcohol por aceite de linaza. Pero además, Ruffner ${ }^{30}$ cita que Newton en los Principia había conjeturado que el calor del hierro al rojo vivo era tres o cuatro veces el de ebullición del agua. Esto podría ser una mera suposición, o bien que ya hubiera hecho alguna medida preliminar, que es lo que estima como más probable. Al final, como ya hemos expuesto, concluye Ruffner que "la conjetura se elevó a un principio básico en 1690 como resultado de una cuidadosa experimentación y mediciones".

En cualquier caso, Newton formula la ley del calor como una ley básica de la naturaleza.

\section{ANEXO}

\section{SCALA GRADUUM CALORIS}

En la primera columna de esta tabla están los grados de calor en proporción aritmética, comenzando por el calor con el que el agua empieza a helarse como grado de calor mínimo o límite común entre calor y frío, y poniendo que el calor humano externo sea la parte duodécima. En la segunda columna están los grados de calor en razón geométrica, de manera que el segundo grado sea el doble del primero, el tercero lo mismo del segundo y el cuarto, del tercero, y el primero sea el calor externo del cuerpo humano estimado por la sensación. Se ve con esta tabla que el calor del agua hirviendo es casi el triple que el calor del cuerpo humano, y que el calor del estaño fundente es séxtuplo, y que el del plomo fundente óctuplo, y el calor del regulus fundente duodécuplo, y el calor ordinario del fuego de la cocina es dieciséis o diecisiete veces mayor que el calor del mismo cuerpo humano.

Esta tabla se ha construido por medio del termómetro y del hierro candente. Con el termómetro hallé la medida de todos los calores hasta el que funde el estaño, y con el hierro caliente hallé el resto de las medidas. En efecto, el calor que el hierro caliente comunica a los cuerpos fríos contiguos a él tras un tiempo dado, esto es, el calor que el hierro pierde en un tiempo dado, es como el calor de todo el hierro. Por tanto, si se toman tiempos de enfriamiento iguales, los calores estarán en razón geométrica, y por ello se pueden encontrar fácilmente por la tabla de logaritmos.

Así pues, primeramente averigüé con el termómetro de aceite de linaza que si, cuando el termómetro se colocaba en nieve liquescente, el aceite ocupaba un espacio de 1000 partes, el mismo aceite dilatado por el calor de primer grado o del cuerpo humano ocupaba un espacio de 10256; y por el calor del agua a punto de empezar a hervir, un espacio de 10705; y por el calor del agua hirviendo impetuosamente, un espacio de 10725; y por el calor de estaño líquido ardiente cuando empieza a endurecerse y adquirir la consistencia de una amalgama, un espacio de 11516; y cuando endurece, un espacio de 11496 . Así pues, el aceite rarificado era al dilatado por el calor del cuerpo humano como 40 a 39 por el calor del agua en ebullición, como 15 a 14; por el calor del estaño que deja de hervir, cuando empieza a coagularse y endurecerse, como 15 a 13; y por el calor del estaño que ha dejado de hervir y se ha endurecido del todo, como 23 a 20. La rarefacción del aire con el mismo calor era el décuplo mayor que la rarefacción del aceite, y la rarefacción de aceite era casi quince veces mayor que la rarefacción del espíritu de vino. Y a partir de esto, tomando los calores del mismo aceite proporcionales a la rarefacción y asignando 12 partes al calor del cuerpo humano, resulta que el calor del agua cuando comienza a hervir es 33 partes y cuando hierve enérgicamente, 34 partes; y el calor del estaño cuando o bien se funde o cuando al dejar de hervir comienza a endurecer y toma la consistencia de la amalgama, 72 partes; y cuando al dejar de hervir, se torna rígido y duro, 70 partes.

Una vez halladas estas cosas, para investigar el resto, calenté un hierro bastante grueso hasta que estuviera bastante candente, y una vez sacado del fuego con tenazas también candentes, lo coloqué al instante en un lugar frío donde el viento soplaba constantemente $y$, poniendo sobre él partículas de diversos metales y otros cuerpos licuables, anoté los tiempos de enfriamiento hasta que todas las partículas endurecían perdiendo la fluidez y el calor del hierro igualase el calor del cuerpo humano. Suponiendo luego que los excesos de los calores del hierro y de las partículas en solidificación por encima del calor de la atmósfera, halladas con el termómetro, están en progresión geométrica mientras que los tiempos están en progresión aritmética, se determinaron todos los calores. Coloqué el hierro no en aire tranquilo, sino en un viento que fluía uniformemente, para eliminar el aire calentado por el hierro, sustituyéndolo uniformemente por aire frío. De esta manera, en tiempos iguales se calentaban partes iguales de aire, las cuales recibían grados de calor proporcionales al calor del hierro.

Los calores así encontrados mantenían entre sí la misma relación que los calores hallados con el termómetro y por tanto suponemos acertadamente que las dilataciones del aceite son proporcionales a sus calores. 


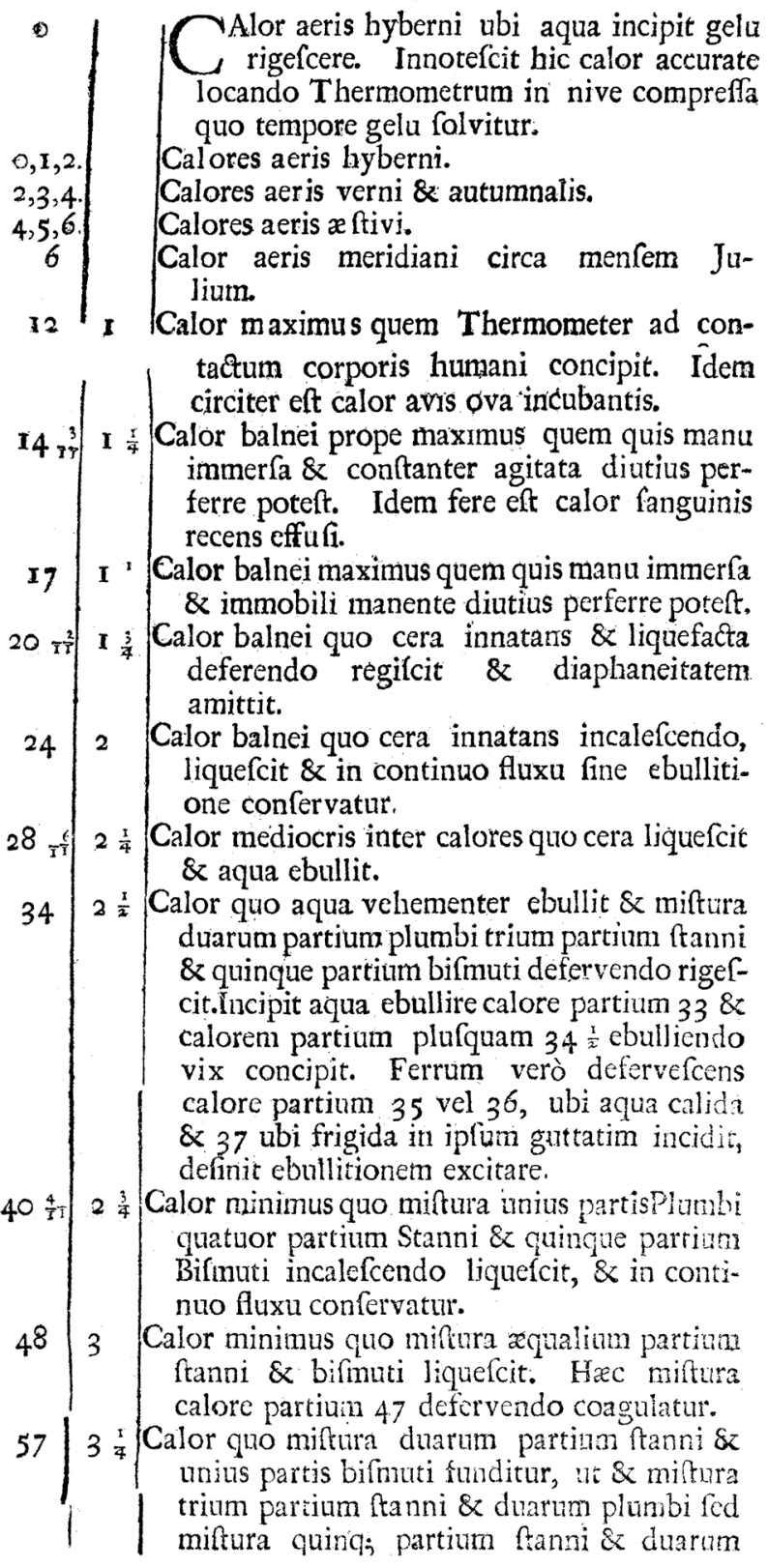

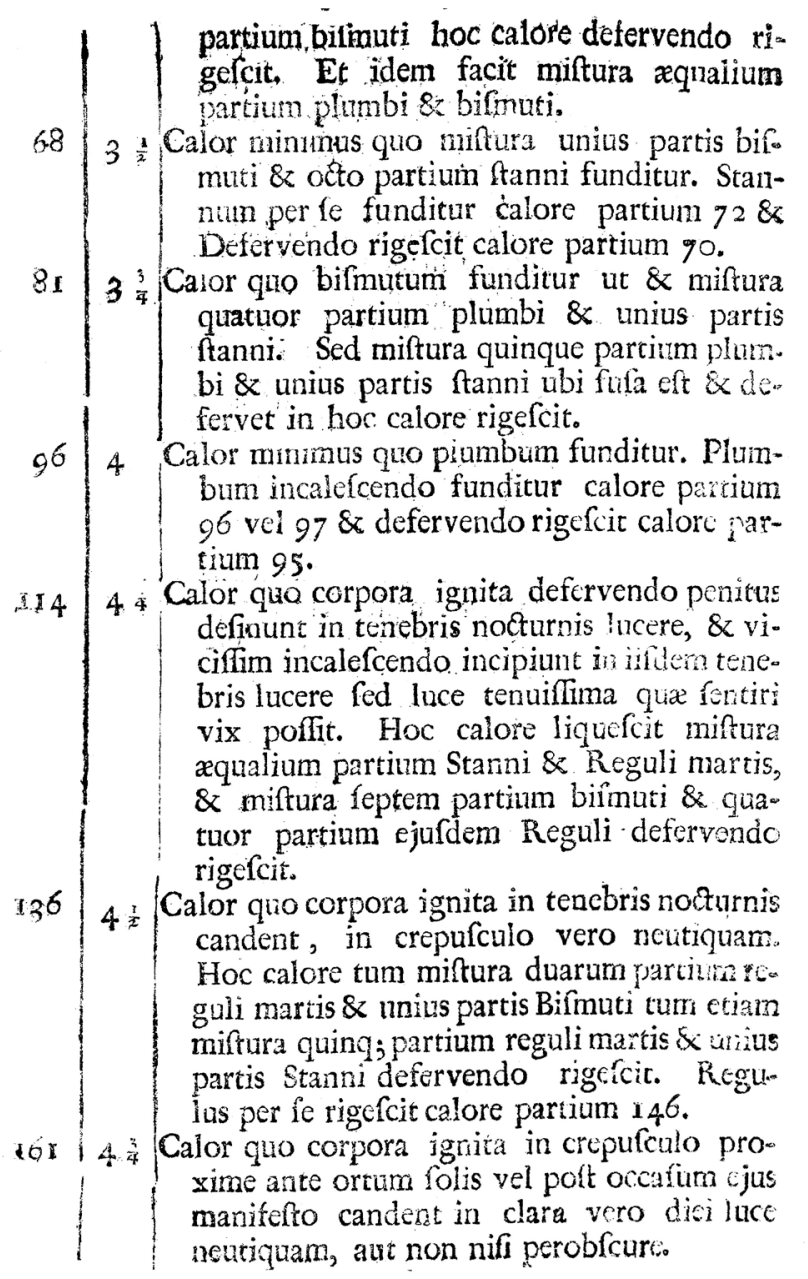

192 5 Calor prunarem in igne parvo culinari ex carbenibus: foffilibus bituminofis conftructo $\$ x$ $\mathrm{ab}\{\mathrm{q} ;$ ufu follium ardente. Idem eft caior ferri in tali igne quantum poteft candentis. Ignis parvi culinaris qui ex lignis conftat calor paulo major eft nempe partium 200 vel 2ro. Et ignis magni majon adhuc eft calor, prafertim fi follibus cieatur.

\section{AGRADECIMIENTOS}

Mi agradecimiento a Manuel Sellés por sus comentarios, siempre acertados, y a Carlos Solís por su imprescindible ayuda con los textos latinos. Asimismo, a Francisco Martínez Bernalte por su ayuda con la confección de las figuras.

\section{NOTAS AL FINAL}

1 Phil. Trans. 1700-1701, Vol. 22, pp. 824-829. Esta reproducido y traducido al inglés en Cohen.

2 Según Brewster el artículo se presentó en la Royal Society el 28 de mayo de 1701.

3 En el Anexo se incluye la traducción de las últimas páginas (827-829 del original), todo ello realizado con la inestimable 
colaboración de Carlos Solís. No conocemos ninguna otra traducción al castellano de la Scala. A continuación, se presenta una figura con la tabla original de la Scala. La traducción de las descripciones de la tercera columna está en la séptima de nuestra Tabla I bajo el nombre de "Estados".

4 Benson (2010a) lleva a cabo un estudio muy pormenorizado de todo ello.

5 Biot es el autor de la entrada Newton (Isaac) en la Biographie Universelle. Ancienne et Moderne, Vol. 31. Paris, 1822. pp. 127-194. La afirmación está en la p. 190 dech. Véase también Higgitt, Cap. 1.

6 Ruffner, p. 152.

7 Ruffner, p. 147.

8 Ruffner, p. 140.

9 Desaguliers (1744), Lecture X, Hydrostaticks, §34, pp. 293-295.

10 Dobbs, 1975: p. 146-147. La reacción de reducción de la estibina, o antimonita, es. El término martis, de Marte, era el sinónimo para el hierro.

11 El primero que distinguió entre calor y temperatura fue Joseph Black (1728-1799), alrededor de 1760. Sin embargo, sus ideas se difundieron lentamente a partir de 1770 y su obra Lectures on the elements of chemistry se publicó después de su muerte en 1803.

12 Véase Patterson

13 Desaguliers. p. 293.

14 Explica que después de la preparación el nivel del aceite llegaba a la marca 7 . Con el agua hirviendo alcanza 12,5 y con las cuatro aleaciones citadas 12,$5 ; 15 ; 25$ y 35 . Para las tres últimas las temperaturas correspondientes en grados centígrados se encuentran en prontuarios, y son 183-224, 232 y 327 드, y para el agua es obviamente 100 으. En cuanto a la primera de las citadas aleaciones no define la proporción de los componentes. Representadas gráficamente el agua y las dos últimas están perfectamente alineadas. Como según manifiesta el volumen entre marcas es $1 / 21$ del bulbo, y la diferencia entre el agua y el plomo son 24 unidades y $227 \stackrel{\circ}{ } \mathrm{C}$, resulta que la dilatación volumétrica es 5·10-3 ㅇ- 1 . En los gráficos que presenta Grigull para una temperatura de 175 o $C$ vale $0,8 \cdot 10-3$, es decir más de seis veces mayor.

15 Desaguliers. p. 294.

16 Desaguliers, p. 295.

17 Grigull, Ver Fig.2, p. 197.

18 Así está definido en el artículo citado. De acuerdo con los datos mostrados en el gráfico se puede expresar de forma lineal como $\beta=\beta_{0}+\beta_{1} T$, donde $\beta_{0}=660 \cdot 10^{-6}$ y $\beta_{1}=0,65 \cdot 10^{-6}$, para que a $100 \stackrel{\circ}{\circ}$ ( 34 o N) resulte $\beta=725 \cdot 10^{-6}$ que es el valor que corresponde al 10725 dado por Newton, con una temperatura ambiente de $15 \stackrel{\circ}{\circ}$.

\section{BIBLIOGRAFÍA}

Benson, Ugo (2010a), The History of the Cooling Law: When the Search for Simplicity can be an Obstacle, Springer Sicence+Business Media B. V.

Benson, Ugo (2010b), “Cooling and warming laws: an exact anaIytical solution”, Eur. J. Phys. 31, pp. 1107-1121.
19 Desarrollada en serie toma la forma $x=\left(\beta T-\beta^{2} T^{2}\right)\left(1+\beta_{a} T_{d}\right)$ $V / S$. Si introducimos la aproximación de $\beta$ dada en el punto anterior, se obtiene, es decir siempre existe una no linealidad intrínseca.

20 El problema tiene varias variantes como expondremos. En todas tomaremos como referencia la ebullición del agua (12A) con 725 partes de expansión y 24 oN equivalentes a100 ㄷ, y obtendremos las temperaturas para las expansiones de 256 y 1516, que recordamos que eran las del cuerpo humano (6) y fusión del estaño (16B). Newton les asigna las temperaturas de 12 y 72 respectivamente, que convertidas directamente a la escala centígrada resultarían 35,29 y $211,76 \stackrel{\circ}{ } \mathrm{C}$ (se toma $1 \mathrm{~N}=0,34 \stackrel{\circ}{ } \mathrm{C}$ por la referencia antedicha). El cálculo con coeficiente de dilatación no constante, con las fórmulas anteriores y los $\beta_{0}$ y dados, nos lleva a 35,79 y 207,16 ․ C. Si el coeficiente de dilatación fuese constante, es decir $\beta_{1}=0$, , esos valores serían 33,79 y 226,26 ㄷ, la diferencia se explica por lo dicho en la nota anterior. Finalmente, si la temperatura de aceite en el tubo fuese igual al del bulbo, que sería el caso lineal estricto, es decir $T_{a}=T$, se obtendría 35,31 y 209,1 ㅇ.

21 Esta tabla es similar a la que presenta Grigull 1984 (p. 197), aunque éste sólo indica una temperatura para cada punto. Los diagramas de fase son de muy amplia difusión.

22 La temperatura absoluta se mide respecto al punto denominado "cero absoluto", en el cual la energía sería nula, y que en la escala centígrada es -273,16 ㅇ Esta escala, también llamada termodinámica, se mide en grados Kelvin ( $\mathrm{K}$ ).

23 Todos dependen de la temperatura del aire. Hemos tomado sus valores a $10 \stackrel{\circ}{ } \mathrm{C}$, que son: $\mathrm{k}=0,024 \mathrm{~W} / \mathrm{mK} ; \rho=1,22 \mathrm{~kg} / \mathrm{m} 3$; $\mu=1,76 \cdot 10-5$; y $\mathrm{cp}=1004 \mathrm{~J} / \mathrm{kgK}$.

24 Su valor es $\sigma=5,6704 \cdot 10-8 \mathrm{~W} / \mathrm{m} 2 \mathrm{~K} 4$.

25 La densidad es $\rho h=7874 \mathrm{~kg} / \mathrm{m} 3$ y el calor específico ce $=450$ $\mathrm{J} / \mathrm{kg} \cdot \mathrm{K}$.

26 El valor 2 en la escala Beaufort, denominado como "brisa muy débil" apunta una velocidad de 4-6 nudos, esto es 2-3 $\mathrm{m} / \mathrm{s}$.

27 Obviamente estos serían los valores que habría medido Newton si en su termómetro el punto de ebullición del agua hubiese sido 100, en vez de los 34 marcados.

28 Sería $M={ }^{\prime} \sum\left(T_{S i}-T_{R i}\right)^{2}$ ' $N$, siendo $N$ el número de puntos. Los valores resultantes son [349 160512883614173668766 2374], correlativamente al número de cada simulación.

29 Calor quem ferrum calefactum corporibus frigidis sibi contiguis dato tempore communicat, hoc est calor quem ferrum dato tempore amittit est ut calor totus ferri.

30 Ruffner, 1963 p. 148. Se refiere al Lib. III en los comentarios a las observaciones al cometa de 1680, denominado Kirch o de Newton. (Principia, ed. Cajori, p. 521).

Brewster, David (1831), The Life of Sir Isaac Newton. Harper \& Brothers, New York.

Brewster, David (1855), Memoirs of the Life, Writings, and Discoveries of Sir Isaac Newton, vol. 2. Edimburgo.

Cohen I. B. (1958), Isaac Newton's Papers \& Letters On Natural Philosophy, Harvard University Press, pp. 259-269. 
Desaguliers, J. T. (1744), A course of Experimental Philosophy, Vol. II, Londres

Dobbs, B. J. T. (1975), The Foundations of Newton's Alchemy, Cambridge University Press.

Grigull, Ulrich (1984), "Newton's Temperature Scale and the Law of Cooling", Wärme und Stoffübertragung, 18, pp. 195-199.

Higgitt, Rebekah (2007), Recreating Newton. Newtonian Biography and the Making of Nineteenth Century History of Science, Pickering \& Chatto Publishers. Londres.

Newton, Isaac. Principia. Traducida al inglés por Andrew Motte's (1729). Revisada por Florian Cajori. University of California Press, 1934.
Newton, Isaac (anónimo). "Scala graduum Caloris. Calorum Descriptiones \& signa”, Phil. Trans, 1700-1701, vol. 22, pp. 824-829.

Patterson, Louise Diehl (1951), "Thermometers of the Royal Society, 1663-1768", American Journal of Physics, 19, pp. 523535.

Robert M. Sayre, Norman (1963). "The 'Scala Graduum Caloris' and Sir Isaac Newton", Proc. Of the Okla. Acad. Of Sci. for 1962. Vol. 43, 1963, pp. 198-202.

Ruffner, James A. (1963), "Reinterpretation of the Genesis of Newton's 'Law of Cooling'", Notes and Records of the Royal Society, 18, pp. 138-152. 